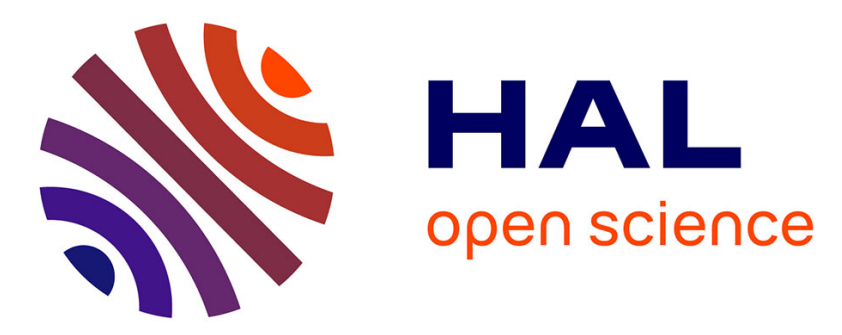

\title{
Influence of activation conditions on textural properties and performance of activated biochars for pyrolysis vapors upgrading
}

Christian Di Stasi, Gianluca Greco, Rafael Luan Sehn Canevesi, M. Teresa Izquierdo, Vanessa Fierro, Alain Celzard, Belen Gonzalez, Joan Manyà

\section{To cite this version:}

Christian Di Stasi, Gianluca Greco, Rafael Luan Sehn Canevesi, M. Teresa Izquierdo, Vanessa Fierro, et al.. Influence of activation conditions on textural properties and performance of activated biochars for pyrolysis vapors upgrading. Fuel, 2020, pp.119759. 10.1016/j.fuel.2020.119759 . hal-03093129

\section{HAL Id: hal-03093129 \\ https://hal.univ-lorraine.fr/hal-03093129}

Submitted on 14 Jan 2021

HAL is a multi-disciplinary open access archive for the deposit and dissemination of scientific research documents, whether they are published or not. The documents may come from teaching and research institutions in France or abroad, or from public or private research centers.
L'archive ouverte pluridisciplinaire HAL, est destinée au dépôt et à la diffusion de documents scientifiques de niveau recherche, publiés ou non, émanant des établissements d'enseignement et de recherche français ou étrangers, des laboratoires publics ou privés. 


\section{Influence of activation conditions on textural}

2 properties and performance of activated biochars

\section{3 for pyrolysis vapors upgrading}

4 Christian Di Stasi ${ }^{1 *}$, Gianluca Greco ${ }^{1}$, Rafael L. S. Canevesi ${ }^{2}$, M. Teresa Izquierdo ${ }^{3}$, Vanessa

$5 \quad$ Fierro $^{2}$, Alain Celzard ${ }^{2}$, Belén González ${ }^{1}$, Joan J. Manyà

$6{ }^{1}$ Aragón Institute of Engineering Research (I3A), Thermochemical Processes Group,

7 University of Zaragoza, Technological College of Huesca, Crta. Cuarte s/n, 22071 Huesca,

8 Spain

$9 \quad{ }^{2}$ Université de Lorraine, CNRS, IJL, Épinal, F-88000, France

$10{ }^{3}$ Instituto de Carboquímica (ICB-CSIC), Miguel Luesma Castán 4, Zaragoza, E-50018, Spain

$12{ }^{*}$ Corresponding author at: Aragón Institute of Engineering Research (I3A), Thermochemical

13 Processes Group, University of Zaragoza, Technological College of Huesca, Crta. Cuarte s/n,

1422071 Huesca, Spain

15 E-mail address: christiandistasi@ unizar.es. 


\section{ABSTRACT}

17 The main aim of the present study is to provide a comprehensive assessment of the effects of

18 process activation conditions on the textural properties of the resulting activated carbons,

19 which were produced from wheat straw-derived biochar through chemical activation (with

$20 \mathrm{~K}_{2} \mathrm{CO}_{3}$ at different pressures and mass impregnation ratios) and physical activation (with $\mathrm{CO}_{2}$

21 at different temperatures and pressures). For chemically activated biochars, it was found that 22 specific surface area and pore size distribution were both only positively affected by 23 increasing the carbonate loading. However, physically activated biochars produced at the 24 highest pressure and lowest temperature $\left(1.0 \mathrm{MPa}\right.$ and $\left.700{ }^{\circ} \mathrm{C}\right)$ had the highest surface areas 25 and widest pore size distributions. The materials with the most appropriate textural properties 26 were then tested as catalysts for steam and dry reforming of the aqueous phase of pyrolysis 27 oil. The best catalytic performance (a total gas yield of $74 \%$ and a selectivity toward $\mathrm{H}_{2}$ of 28 almost $40 \%$ ) was observed for a physically activated biochar. This good performance was 29 ascribed to the high availability of $\mathrm{K}^{0}$ on the catalyst surface, which could effectively 30 promote the reactions involved in the upgrading process.

\section{Keywords}

32 Biochar; chemical activation; $\mathrm{K}_{2} \mathrm{CO}_{3}$; physical activation; pressure; steam and dry reforming 33 of pyrolysis oil 
In recent years, the demand for activated carbons has increased due to their usefulness in a wide range of different applications such as gas and liquid purification [1], electrochemistry [2], soil remediation [3] and catalysis [4]. Thanks to their versatility to be adapted to specific applications, these materials are considered promising candidates to address environmental issues related to global warming and pollution [5]. Nevertheless, the current main drawback is that the production of activated carbons is still partly based on fossil fuels, which do not meet sustainability criteria [6,7]. Hence, much more efforts should be made to produce much more carbons from biomass. However, the direct conversion of biomass feedstock into the final product has a low yield. Thus, the production of activated carbons from biochar produced by slow pyrolysis seems to be more appropriate in terms of scalability, while at the same time these value-added materials can strengthen the value chain of existing biochar production systems.

In general, pristine biochar has neither a well-developed surface area nor a hierarchical pore size distribution, which is mainly dominated by narrow pores with a diameter $\left(d_{p}\right)$ lower than $0.7 \mathrm{~nm}$ (ultra-micropores). Hence, a subsequent activation step is required to improve the textural properties of the carbon material. The activation process involves the development and opening of the porosity of a char using an activation agent. Depending on the agent used, the procedure can be called chemical or physical activation. Chemical activation usually involves two steps. First, the biochar is impregnated with an aqueous solution of the chemical activation agent, or mixed with it in the dry state, and, in a second step, the blend is heated up to a given temperature at which oxidation, dehydration, aromatization and crosslinking reactions, among others, occur. Although the most widely used chemical reagents are $\mathrm{KOH}$ [8] and $\mathrm{H}_{3} \mathrm{PO}_{4}$ [9], non-hazardous and relatively cheap 
Mai et al. [12] have recently reported that activation with potassium carbonate can result in carbons with a high percentage of structural defects and a well-balanced porosity between micro- and mesopores.

When activation is carried out by exposing the precursor to relatively high temperatures under an oxidizing atmosphere (e.g., $\mathrm{CO}_{2}[13], \mathrm{H}_{2} \mathrm{O}$ [14] and $\mathrm{O}_{2}$ [15]), the process is called physical activation. Through either physical or chemical activation, it is possible to tune the textural features of the starting biochar by properly adjusting the activation conditions, mainly temperature, type and/or concentration of activation agent, as well as pressure. To the best of our knowledge, although both activation procedures are widely reported in the literature, a thorough study on the effects that the activation parameters and their possible interactions have on the textural properties of the resulting activated biochar, has never been reported so far. Such information could be very helpful to properly establish the most appropriate operating conditions to produce engineered carbon materials from biomass.

One of the most interesting fields of application of activated carbons is the upgrading of raw pyrolysis vapors, which contain both permanent gases (e.g., $\mathrm{CO}_{2}, \mathrm{CO}, \mathrm{CH}_{4}$, and $\mathrm{H}_{2}$ ) and condensable compounds. The condensable fraction, which is generally called pyrolysis oil or bio-oil, is a mixture of hundreds of organic compounds (alcohols, ketones, acids, etc.) and water, and its composition strictly depends on the biomass composition and the pyrolysis operating conditions [16]. For biochar production systems based on slow pyrolysis, downstream processes aimed at upgrading pyrolysis vapors are required to avoid undesirable condensation of organic compounds and to increase simultaneously the quality of the gaseous product. For this purpose, combined steam and dry reforming of pyrolysis oil is a promising option $[17,18]$, due to the presence of a relatively high amount of $\mathrm{CO}_{2}$ and steam in the raw vapor phase. Heterogeneous catalysts based on transition metals such as Ni [19,20], Co [21],

84 Pt and Rh [22] can be used to improve the overall conversion and the selectivity of the 
products. However, the main drawback of these catalysts is that the relatively expensive active phase can easily be poisoned and/or deactivated by deposition of coke [23]. One possible solution to reduce the overall cost of the upgrading process is to use activated biochar as catalyst. Its porous structure and inherent inorganic contents (especially $\mathrm{K}, \mathrm{Mg}$ and Ca) could result in a relatively good catalytic activity [24-29]. Furthermore, due to the presence in the reaction system of $\mathrm{H}_{2} \mathrm{O}$ and $\mathrm{CO}_{2}$, the carbonaceous support, as well as coke deposits, could be continuously partly gasified, thus creating new pores to avoid deactivation. In addition, the spent biochar can be burned to recover energy [30] or, depending on the metal loaded on the support, employed as soil conditioner [31].

Keeping in mind all the above, the main objective of this study was to perform a preliminary investigation about the effects of several activation conditions on the textural properties and the catalytic activity of the resulting activated biochars. To this end, wheat straw-derived biochar was activated chemically and physically with $\mathrm{K}_{2} \mathrm{CO}_{3}$ and $\mathrm{CO}_{2}$, respectively, under different operating conditions. To objectively assess the effect of the selected operation conditions (temperature and mass ratio $\mathrm{K}_{2} \mathrm{CO}_{3} /$ precursor for chemical

100 activation, and temperature and pressure for $\mathrm{CO}_{2}$ activation), we implemented two factorial designs of experiments, with two factors and three replicates at the center point. The specific surface areas and pore size distributions of the resulting activated biochars were then evaluated. The most promising activated biochars were finally tested as catalysts for steam and dry reforming of pyrolysis oil. Their performance was evaluated in terms of conversion of liquid into gas, product selectivity and resistance to deactivation.

\section{Experimental Section}

This study was divided into two main steps: in the first, we carried out physical and chemical activations under different process conditions in order to study their influence on the pore size distribution and specific surface area of the resulting activated biochars; in the 
110 second part, the most promising materials were then tested as catalysts in pyrolysis vapors

111 upgrading experiments. The methodology used in this study is summarized graphically in

112 Fig. A.1.

\section{2.1. Biochar production}

114 The biochar used in this study was produced by slow pyrolysis of binder-free wheat straw

115 pellets (9 mm OD and 10-13 mm long). Pyrolysis was carried out at atmospheric pressure in

116 a fixed bed reactor, which was placed inside a furnace and heated up to $500{ }^{\circ} \mathrm{C}$ at an average

117 heating rate of $5{ }^{\circ} \mathrm{C} \min ^{-1}$ and using $\mathrm{N}_{2}$ as carrier gas. More details on the pyrolysis device

118 and the experimental procedure are available elsewhere [32]. The resulting biochar (i.e.,

119 "pristine") was ground and then thoroughly sieved to obtain particle sizes in the range of

$120 \quad 0.212$ to $1.41 \mathrm{~mm}$. The pristine biochar was characterized by proximate analysis (performed

121 in quadruplicate according to ASTM standards D3173 for moisture, D3174 for ash, and

122 D3175 for volatile matter) and ultimate analysis by means of an elemental analyzer CHN628

123 from Leco Corporation (USA).

\section{2.2. Activation of pristine biochar}

125 2.2.1. Chemical activation

126 For chemical activation, the pristine biochar was first impregnated with a $1 \mathrm{~mol} \mathrm{~L}^{-1}$ aqueous solution of $\mathrm{K}_{2} \mathrm{CO}_{3}$. Three $\mathrm{K}_{2} \mathrm{CO}_{3}$ : biochar mass impregnation ratios $(1: 1,2: 1$ and 3:1) were achieved by adjusting the volume of solution. The heterogeneous mixture was then stirred for $2 \mathrm{~h}$ at $50{ }^{\circ} \mathrm{C}$, filtered and dried overnight at $110{ }^{\circ} \mathrm{C}$ to remove the residual water.

130 Afterwards, $10 \mathrm{~g}$ of the impregnated samples were heated up to $700{ }^{\circ} \mathrm{C}$ at a heating rate of 10

$131{ }^{\circ} \mathrm{C} \min ^{-1}$, under an inert atmosphere $\left(\mathrm{N}_{2}\right)$, and at three different values of absolute pressure $132(0.10,0.55$ and $1.00 \mathrm{MPa})$. For this purpose, a tubular fixed bed reactor (made of nickel133 chromium alloy UNS N06600, $28.1 \mathrm{~mm}$ ID and $600 \mathrm{~mm}$ long) placed in a vertical furnace 134 (model EVA 12/300 from Carbolite Gero, UK) was used. The relatively low activation 
temperature was chosen to avoid the evaporation of the metallic potassium derived from the decomposition of the activation agent and, also, to ensure low activation extensions and

137 clearly see the potential effects of the studied parameters. On the other hand, the range of 138 activating pressures was chosen in order to allow this experimental setup to be easily scaled 139 up, since the involved pressures were not too high (up to 1.0 MPa). A soaking time at the 140 highest temperature of 60 min was set. The pressure within the reactor was adjusted using a 141 downstream servo-controlled regulator valve. The gas hourly space velocity (GHSV) at the 142 activation temperature was estimated to be $7000 \mathrm{~h}^{-1}$, considering the pressure applied and a 143 bed void factor of 0.5 . Thus, the mass flow rate of the inlet gas stream $\left(\mathrm{N}_{2}\right)$ was properly 144 adjusted as a function of the selected pressure and the highest temperature to achieve the 145 aforementioned GHSV value.

146 As a last step, the carbons were rinsed to remove the unreacted reagent and other

147 impurities from their surface. In this work, two different washing procedures were adopted to 148 assess possible effects on the resulting surface area and the catalytic activity of the activated 149 carbons produced. For this purpose, among all the unwashed chemically activated biochars, 150 four of them were just washed with hot deionized water $\left(100^{\circ} \mathrm{C}\right)$, while the seven chemically 151 activated biochars adopted in the design of experiments were washed with a $0.25 \mathrm{~mol} \mathrm{~L}^{-1}$ solution of $\mathrm{HCl}$ followed by hot water. Both washing procedures were carried out until neutral $\mathrm{pH}$. The resulting activated biochars were then dried overnight at $110{ }^{\circ} \mathrm{C}$. The

154 efficiency of the washing step was evaluated according to the washing yield, calculated from

155 Eq. 1, in which $m_{c}$ and $m_{w}$ are the masses of activated carbon before and after the washing steps, respectively.

$$
Y_{\text {wash }}=\left(1-\frac{m_{c}-m_{w}}{m_{c}}\right) 100
$$


Physically activated biochars were produced under an atmosphere of pure $\mathrm{CO}_{2}$ at three different temperatures $\left(700,775\right.$ and $\left.850{ }^{\circ} \mathrm{C}\right)$, and at three different absolute pressures $(0.10$,

1610.55 , and $1.00 \mathrm{MPa}$ ). The selected activation temperatures are within the range commonly 162 reported in the literature, whereas the pressure values were established with the purpose to 163 compare the properties of resulting activated carbons produced under atmospheric and 164 moderate pressures. Using the same device described in the previous section, $10 \mathrm{~g}$ of pristine biochar were heated under $\mathrm{N}_{2}$ atmosphere, at a heating rate of $10{ }^{\circ} \mathrm{C} \mathrm{min}^{-1}$, until the target temperature was reached. Then, the gas supply was switched from $\mathrm{N}_{2}$ to $\mathrm{CO}_{2}$ at a constant GHSV of $7000 \mathrm{~h}^{-1}$. These conditions were maintained during the time required to reach a degree of burnout ( $\eta$, defined as the percentage of mass loss) in the range of $30 \%$ to $60 \%$.

\subsubsection{Design of experiments}

To objectively assess the effects of the activation conditions on the textural properties of activated biochars, an unreplicated two-level factorial design of experiments (with two factors and three replicates at the center point) was adopted for both chemical and physical activations. For chemical activation, the analyzed factors were the absolute pressure and the impregnation ratio of $\mathrm{K}_{2} \mathrm{CO}_{3}$ to raw biochar, whereas in the case of physical activation, the temperature and the absolute pressure were the studied factors. The structure of the regression model used in the statistical analysis was the following:

$$
\hat{\mathrm{y}}=\beta_{0}+\beta_{i} A+\beta_{j} B+\beta_{i j} A B
$$

178 where $A$ and $B$ corresponded to the assessed factors (normalized values in the range from -1

179 to 1 ), whereas $\beta_{0}, \beta_{i}$, and $\beta_{i j}$ were the intercept, linear, and interaction coefficients, respectively. The results obtained for the selected response variables (y) were analyzed using

181 the Minitab v17 statistical package. A significance level of 5\% was assumed and the adjusted 182 coefficient of determination $\left(R_{a d j}^{2}\right)$ was taken as an indicator of the quality of the fit. Table 1 183 summarizes the adopted designs of experiments and lists the names of the activated biochars 
184 produced. Briefly, activated biochar are referred as $X_{-} Y_{-} P . X$ corresponds to the activation procedure (CB or $\mathrm{PB}$ for chemically activated biochar and physically activated biochar, respectively); $Y$ is the activation temperature for $\mathrm{PBs}$ or the impregnation ratio for $\mathrm{CBs}$; and $P$

187 is the activation pressure.

\subsection{Catalytic pyrolysis vapors upgrading}

The liquid feed used here for pyrolysis vapors upgrading tests was the filtered aqueous phase of the pyrolysis oil formed during the production of pristine biochar derived from wheat straw. This resulting liquid product was characterized in terms of elemental composition, using the same $\mathrm{CHN}$ analyzer as mentioned in section 2.1 , and water content, using a volumetric Karl-Fischer titrator Titrino plus 870 from Metrohm (Switzerland).

A schematic overview of the experimental device used for the reforming tests is shown in Fig. A.2 (Appendix A). The reactor and furnace elements were the same as those previously described in section 2.2. The reforming operating conditions were selected based on the findings of a previous study [33], which aimed to establish the best process conditions to minimize deactivation by coke deposition.

Briefly, activated biochar (2-5 g) was loaded into the reactor and heated under $\mathrm{N}_{2}$ atmosphere at an absolute pressure slightly above $0.1 \mathrm{MPa}$. Once the bed temperature reached the target value of $750{ }^{\circ} \mathrm{C}, \mathrm{CO}_{2}$ was added to the inlet gas stream at a partial $\mathrm{CO}_{2}$ pressure of $0.02 \mathrm{MPa}$. The liquid feed was then injected into the gas stream at the inlet of the reactor by means of a HPLC pump (model 521 from Analytical Scientific Instruments, USA). The liquid hourly space velocity (LHSV) was kept constant and equal to $2 \mathrm{~h}^{-1}$ for all the experiments conducted. The duration of the experiments was $60 \mathrm{~min}$. The reactor outlet stream, consisting of permanent gases, unreacted pyrolysis oil, and condensable side products, was forced to pass through an ice-bath condensation train. The permanent gases were analyzed using a dual-channel micro gas chromatograph ( $\mu$-GC 490 from Agilent, 
209 USA) equipped with TCD detectors and two analytical columns (a Molsieve 5 A and a

210 PolarPlot $\mathrm{U})$. The known amount of $\mathrm{N}_{2}$ fed was used as a tracking compound to calculate the

211 yield of produced gas.

212 Table 1. Matrix of the factorial designs adopted to assess the effects of the selected factors

213 during both chemical and physical activations. For example, a physical activation carried out

214 at $\mathrm{A}=-1$ and $\mathrm{B}=1$ means that the process was performed at $700^{\circ} \mathrm{C}$ and $1.0 \mathrm{MPa}$

\begin{tabular}{|c|c|c|c|}
\hline \multicolumn{4}{|c|}{ Chemical activation } \\
\hline \multicolumn{4}{|c|}{ (thermal treatment under $\mathrm{N}_{2}$ up to $700{ }^{\circ} \mathrm{C}$ and $1 \mathrm{~h}$ soaking time) } \\
\hline & \multicolumn{2}{|c|}{ Factors } & \multirow{2}{*}{$\begin{array}{c}\text { Response Variables } \\
S_{2 D-N L D F T}, V_{t}, V_{\text {ultra }}, V_{\text {micro }}, V_{\text {meso }}\end{array}$} \\
\hline & $A$ & $B$ & \\
\hline Level & $\begin{array}{l}\text { Pressure } \\
(\mathrm{MPa})\end{array}$ & Mass ratio $\left(\mathrm{K}_{2} \mathrm{CO}_{3}\right.$ : rc & \\
\hline Low $(-1)$ & 0.10 & $1: 1$ & \\
\hline Middle (0) & 0.55 & $2: 1$ & \\
\hline $\operatorname{High}(+1)$ & 1.00 & $3: 1$ & \\
\hline Runs & & & $\begin{array}{c}\text { Activated biochar designation } \\
\text { (all washed with an acidic solution) }\end{array}$ \\
\hline 1 & 0 & 0 & CB_2_0.55 \\
\hline 2 & -1 & +1 & CB_3_0.10 \\
\hline 3 & +1 & +1 & CB_3_1.00 \\
\hline 4 & 0 & 0 & CB_2_0.55 \\
\hline 5 & 0 & 0 & CB_2_0.55 \\
\hline 6 & -1 & -1 & CB_1_0.10 \\
\hline 7 & +1 & -1 & CB_1_1.00 \\
\hline \multicolumn{4}{|c|}{ Physical activation } \\
\hline & \multicolumn{2}{|r|}{ Factors } & Response Variables \\
\hline & $A$ & B & $S_{2 D-N L D F T}, V_{t}, V_{\text {ultra }}, V_{\text {micro }}, V_{\text {meso }}$ \\
\hline Level & $\begin{array}{l}\text { Temperature } \\
\left({ }^{\circ} \mathrm{C}\right)\end{array}$ & $\begin{array}{l}\text { Pressure } \\
(\mathrm{MPa})\end{array}$ & \\
\hline Low $(-1)$ & 700 & 0.10 & \\
\hline Middle (0) & 775 & 0.55 & \\
\hline $\operatorname{High}(+1)$ & 850 & 1.00 & \\
\hline Runs & & & Activated biochar designation \\
\hline 1 & -1 & -1 & PB_700_0.10 \\
\hline 2 & -1 & +1 & PB_700_1.00 \\
\hline 3 & +1 & +1 & PB_850_1.00 \\
\hline 4 & 0 & 0 & PB_775_0.55 \\
\hline 5 & 0 & 0 & PB_775_0.55 \\
\hline 6 & +1 & -1 & PB_850_0.10 \\
\hline 7 & 0 & 0 & PB_775_0.55 \\
\hline
\end{tabular}


$218\left(Y_{g}\right)$ and hydrogen yield $\left(Y_{H 2}\right)$, as defined by Eqs. (3) and (4), respectively.

$$
Y_{g}=\frac{m_{g}}{m_{L}} 100
$$

$$
\begin{aligned}
& \mathrm{Y}_{\mathrm{H} 2}=\frac{\mathrm{F}_{\mathrm{H} 2 \mathrm{av}}}{\mathrm{F}_{\mathrm{H} 2 \text { stoi }}} 100 \\
& \mathrm{~F}_{\mathrm{H} 2 \text { stoi }}=\left(2 \mathrm{n}+\frac{\mathrm{m}}{2}-\mathrm{k}\right) \mathrm{F}_{\mathrm{BO}} \\
& \mathrm{S}_{i}=\frac{\mathrm{n}_{\mathrm{i}}}{\mathrm{n}_{\text {tot }}} 100
\end{aligned}
$$

In Eq. (3), $m_{g}$ was the cumulative mass of the gas produced during the 60-min experiments, whereas $m_{L}$ corresponded to the total mass of the liquid fed. In Eq. (4), $F_{H 2 a v}$ was the experimental average molar flow rate of hydrogen from minute 20 to minute 40 .

$F_{H 2 s t o i}$, which was calculated according to Eq. (5), corresponded to the stoichiometric molar

flow rate of hydrogen considering the contribution from steam reforming reaction. $F_{B O}$ was the molar flow rate of the dry pyrolysis oil fed. The selectivity towards specific gaseous products $\left(S_{i}\right)$ was calculated according to Eq. (6), in which $n_{t o t}$ was the sum of the gaseous products in moles at the outlet stream.

\subsection{Characterization of carbon materials}

The textural properties of pristine and activated biochars were determined from both $\mathrm{N}_{2}$ and $\mathrm{CO}_{2}$ adsorption isotherms at $-196{ }^{\circ} \mathrm{C}$ and $0{ }^{\circ} \mathrm{C}$, respectively. Around $120 \mathrm{mg}$ of sample were degassed under vacuum at $150{ }^{\circ} \mathrm{C}$. ASAP 2020 and ASAP 2420 automatic adsorption analyzers (Micromeritics, USA) were used. The results obtained from the isotherms were treated using the MicroActive software. We determined the BET area $\left(A_{B E T}\right)$ by application of the BET model, as well as the Gurvitch volume $\left(V_{0.97}\right)$. The enhanced 2D-NLDFT model [34] was employed using SAIEUS software (available at www.nldft.com) to evaluate the pore size distributions (PSDs) and other related parameters: surface area $\left(S_{2 D-N L D F T}\right)$, ultra-micropore 
volume $\left(V_{\text {ultra }}, d_{p}<0.7 \mathrm{~nm}\right)$, micropore volume $\left(V_{\text {micro }}, d_{p}<2 \mathrm{~nm}\right)$, total pore volume $\left(V_{t}\right)$ and mesopore volume ( $V_{\text {meso }}, d_{p}$ in the range of 2 to $50 \mathrm{~nm}$ ). The latter was calculated as the difference between $V_{t}$ and $V_{\text {micro }}$.

To evaluate the availability of residual potassium carbonate on the surface of chemically activated biochars, Fourier-transform Infrared Spectroscopy (FTIR) analyses were conducted using a Frontier MIR/NIR Spectrometer from PerkinElmer (USA).

Qualitative temperature-programmed desorption (TPD) analyses of pristine biochar and fresh catalysts used in reforming tests were also performed to assess the thermal stability of these samples. TPD measurements were carried out using a thermogravimetric analyzer coupled with a mass spectrometer (STA 449 F3 and QMS 403 Aëolos Quadro from Netzsch, Germany), by heating the sample up to $750{ }^{\circ} \mathrm{C}$ at a heating rate of $5{ }^{\circ} \mathrm{C} \min ^{-1}$ under an $\mathrm{Ar}$ atmosphere.

A FEI XL30 SFEG scanning electron microscope coupled with energy-dispersive X-ray spectroscopy (Oxford Instrument EDS SDD XMAX detector) was used to characterize the surface of fresh and spent activated biochars. The secondary electron images were taken with an acceleration voltage of 3 or $5 \mathrm{kV}$ to investigate the topology of the samples surface, while an acceleration tension of $10 \mathrm{kV}$ was applied to carry out the chemical mapping of the materials by EDX analysis. Additionally, X-ray photoelectron spectroscopy (XPS) data of spent and fresh catalysts were recorded using an ESCAPlus OMICROM system equipped with a hemispherical electron energy analyzer, following the procedure detailed elsewhere [35].

\section{Results and discussion}

The results of the textural characterization as well as the proximate and ultimate analyses 
NLDFT confirm that the porosity of the pristine biochar, as previously stated, was characterized by a very high fraction of ultra-micropores.

\subsection{Chemical activation}

Although the use of $\mathrm{K}_{2} \mathrm{CO}_{3}$ as catalyst in coal gasification processes has been widely reported in the literature [10-12,33], the mechanism explaining its interaction with the carbon matrix still remains unclear. The main reactions that probably occur during chemical activation of a carbonaceous material are the following:

The increase in specific surface area could be ascribed to the $\mathrm{CO}_{2}$ released from carbonate

decomposition (Reaction 7), which can diffuse into the solid structure and subsequently react with carbon, thereby stimulating the production of $\mathrm{CO}$ by the reverse Boudouard reaction (Reaction 8) and creating vacancies in the solid structure [36]. Despite the fact that the decomposition of $\mathrm{K}_{2} \mathrm{CO}_{3}$ mainly occurs at temperatures above $900{ }^{\circ} \mathrm{C}$, its contact with the carbon matrix can promote its decomposition a relatively low temperatures $[37,38]$. The potassium oxide resulting from the decomposition of the carbonate, or the carbonate itself, can also react with the carbon-based material through Reaction 9 and 10 towards $\mathrm{CO}$ and metallic potassium [39].

The assessed textural properties of chemically activated biochars are listed in Table 2. Fig. 1 shows the normalized plots of the standardized effects for the response variables considered: $S_{2 D-N L D F T}, V_{t}, V_{\text {ultra }}, V_{\text {micro }}$, and $V_{\text {meso }}$. The PSDs obtained for biochars activated 
289 in Figs. A.3a and A.4, respectively. More detailed statistical outcomes for the results reported 290 in the present section can be found in Table A.2.

291 
292 Table 2. Results of textural characterization and washing efficiency of chemically activated 293 biochars

\begin{tabular}{|c|c|c|c|c|c|c|c|c|}
\hline \multirow{3}{*}{ Material } & \multicolumn{2}{|c|}{$\begin{array}{c}\text { Specific surface } \\
\text { area }\end{array}$} & \multicolumn{5}{|c|}{ Pore volumes } & \multirow{3}{*}{$\begin{array}{c}\text { Washing } \\
\text { yield } \\
Y_{\text {wash }} \\
\%\end{array}$} \\
\hline & $A_{B E T}$ & 2D-NLDFT & $V_{0.97}$ & $V_{t}$ & $V_{\text {ultra }}$ & $V_{\text {micro }}$ & $V_{\text {meso }}$ & \\
\hline & \multicolumn{2}{|c|}{$\mathrm{m}^{2} \mathrm{~g}^{-1}$} & \multicolumn{5}{|c|}{$\mathrm{cm}^{3} \mathrm{~g}^{-1}$} & \\
\hline CB_1_0.10 & 170 & 712 & 0.078 & 0.181 & 0.143 & 0.175 & $0.006(3.19 \%)^{a}$ & 77.0 \\
\hline CB_1_0.10_W ${ }^{b}$ & 142 & 700 & 0.068 & 0.180 & 0.135 & 0.169 & $0.011(6.14 \%)^{a}$ & 77.1 \\
\hline CB_1_1.00 & 180 & 761 & 0.081 & 0.195 & 0.149 & 0.188 & $0.007(3.82 \%)^{a}$ & 76.4 \\
\hline CB_1_1.00_W $b$ & 100 & 700 & 0.049 & 0.168 & 0.144 & 0.160 & $0.008(5.01 \%)^{a}$ & 78.1 \\
\hline CB_3_0.10 & 413 & 933 & 0.181 & 0.259 & 0.197 & 0.246 & $0.013(4.96 \%)^{a}$ & 54.3 \\
\hline CB_3_0.10_W ${ }^{b}$ & 368 & 893 & 0.158 & 0.242 & 0.193 & 0.229 & $0.013(5.35 \%)^{a}$ & 56.0 \\
\hline CB_3_1.00 & 337 & 834 & 0.148 & 0.230 & 0.169 & 0.218 & $0.012(5.23 \%)^{a}$ & 56.9 \\
\hline CB_3_1.00_W ${ }^{b}$ & 316 & 851 & 0.138 & 0.229 & 0.180 & 0.217 & $0.012(5.40 \%)^{a}$ & 60.6 \\
\hline CB_2_0.55 & 316 & 900 & 0.137 & 0.238 & 0.180 & 0.228 & $0.009(3.92 \%)^{a}$ & 58.1 \\
\hline CB_2_0.55 & 310 & 872 & 0.136 & 0.233 & 0.177 & 0.222 & $0.011(4.63 \%)^{a}$ & 54.4 \\
\hline CB_2_0.55 & 307 & 864 & 0.137 & 0.233 & 0.171 & 0.221 & $0.011(4.86 \%)^{a}$ & 55.5 \\
\hline
\end{tabular}

$294{ }^{a}$ Calculated as $\frac{\text { Vmeso }}{V t} 100$

$295{ }^{b}$ Carbons just washed with water that were not included in the design of experiments. 

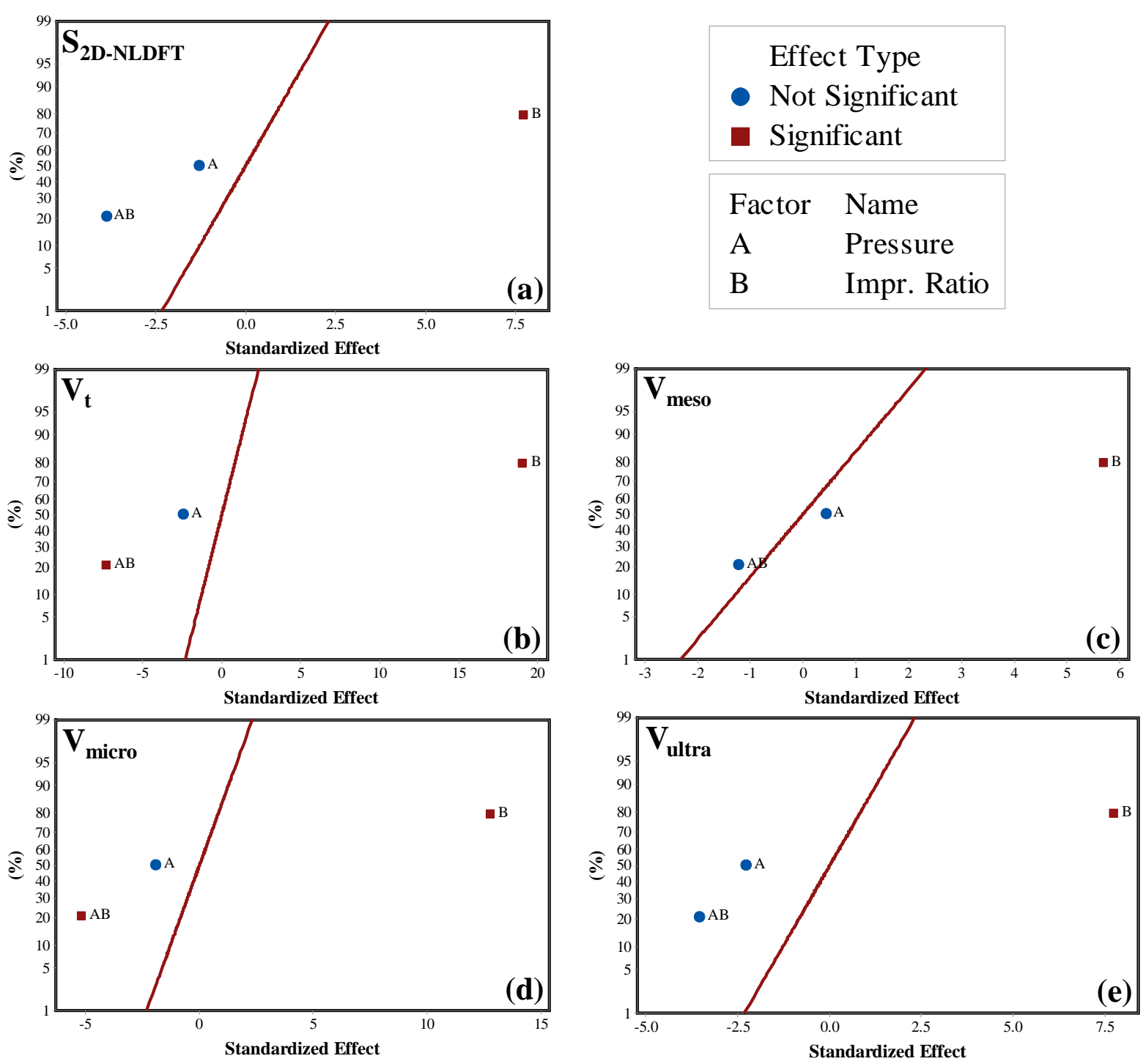

297 Fig. 1. Normal plots of standardized effects $(\alpha=0.05)$ for chemically activated biochars: specific surface area (a); total pore volume (b); mesopore volume (c); micropore volume (d); ultra-micropore volume (e).

300 Regarding the results obtained in terms of specific surface area $\left(S_{2 D-N L D F T}\right)$, Fig. 1a clearly

301 shows that a higher concentration of activation agent led to a significant increase in the porosity of the resulting activated biochars. In contrast, the absolute pressure proved to be irrelevant for the values of final specific surface area. Our results regarding the development

304 of porosity when higher impregnation ratios were used confirm the relevance of $\mathrm{K}_{2} \mathrm{CO}_{3}$ as a 305 chemical reagent for the production of tailored activated carbons. All pore volumes analyzed 306 in the present study were also found to be strongly dependent on the amount of activating 
agent (see Fig. 1). The chemical activation process was able to slightly broaden the original pore size distribution of the pristine biochar, leading to a more hierarchical porous structure with a large contribution of ultra-micropores and a slightly increased amount of mesopores.

310 Almost all the carried out $\mathrm{N}_{2}$ isotherms required more than $70 \mathrm{~h}$ to be completed, thus

311 confirming the predominant narrow microporous structure of chemically activated biochars

312 (see Fig. A.3a), which hindered the diffusion of $\mathrm{N}_{2}$ within the porosity. For both total and micropore volumes, a statistically significant combined effect of pressure and impregnation

314 ratio $(\mathrm{AB})$ was found. However, these effects were comparatively much weaker than that 315 observed for the main effect of the impregnation ratio (B). From a thermodynamics point of 316 view, an increased pressure shifts the equilibrium of the activation reactions to the left. The 317 fact that the textural properties of the resulting activated carbons were practically independent of pressure could indicate that the chemical activation process was mainly 319 kinetically controlled.

320 It should be pointed out that the overall curvature terms for $S_{2 D-N L D F T}, V_{t}$ and $V_{\text {micro }}$ were 321 statistically significant ( $p$-values below 0.05 , as reported in Table A.2). This indicates that, in 322 further studies, our adopted factorial design should be expanded to a central composite design to be able to evaluate the pure quadratic regression coefficients and then apply Response Surface Methodology (RSM) for optimization purposes.

As shown in Table 2, after the carbons were washed only with hot water, there was a slight decrease in both the specific surface area and the micropore volume, compared to those measured for carbons washed with the acidic solution. This can be explained by the fact that water could not completely remove the remaining carbonate (and other chemical species) from the solid surface, thus causing blockage of some micropores. By focusing on the difference between the washing procedures of activated carbons at the same loadings of $331 \mathrm{~K}_{2} \mathrm{CO}_{3}$, the results reported in Table 2 indicate that a higher activation pressure led to an 
increased amount of product not soluble in water, i.e., to higher $Y_{\text {wash }}$ values. This finding agrees with results reported by Malekshahian et al. [40], who concluded that high gasification pressures can limit the volatilization of potassium.

\subsection{Physical activation}

It must be pointed out that an increase in absolute pressure also implied an increase in the partial pressure of the reactant $\left(\mathrm{CO}_{2}\right)$. In the literature, the effects of absolute pressure and partial pressure of reactant are commonly assessed separately. Nevertheless, and as far as we know, no previous studies have addressed the question of whether activation under pressure can cause textural changes in the resulting physically activated biochars. Activation of biomass-derived carbon had only been studied using supercritical water at high pressure [41], but such conditions are too different from the present ones for allowing some comparison to 343 be done.

Table 3 lists the textural properties of the activated carbons produced, whereas Fig. 2 shows the normal plots of the standardized effects obtained for each response variable. More detailed statistical outcomes are reported in Table A.3. The most relevant PSDs and $\mathrm{N}_{2}$ adsorption isotherms are shown in Figs. A.3b and A.5, respectively. As previously mentioned in section 2.2.2, the activation times (also shown in Table 3) were varied to obtain degrees of burnout in the range of $30 \%$ to $60 \%$, since the gasification rate was strictly dependent on reaction temperature and reactant partial pressure. As expected, the reaction rate was minimal at the lowest temperature $\left(700{ }^{\circ} \mathrm{C}\right)$. In fact, and whatever the pressure applied, an activation

352 time of 180 min was required to reach the desired reaction extent. For activation temperatures 353 of 775 and $850{ }^{\circ} \mathrm{C}$, an activation time of 60 min was enough, except for the material 354 PB_850_1.00, for which this reaction time led to an almost complete gasification of the sample $(\eta=85 \%)$. Hence, the activation time at the highest levels of temperature and pressure was finally set at 30 min to obtain a degree of burnout of $57 \%$. 
357 Table 3. Degrees of burnout activation times and textural properties for physically activated 358 biochars

\begin{tabular}{|c|c|c|c|c|c|c|c|c|c|}
\hline \multirow[t]{2}{*}{ Material } & \multirow{2}{*}{$\begin{array}{c}\text { Activation } \\
\text { time } \\
t_{a c t} \\
\text { min }\end{array}$} & \multirow{2}{*}{$\begin{array}{l}\text { Burnout } \\
\qquad \begin{array}{l}\eta \\
\%\end{array}\end{array}$} & \multicolumn{2}{|c|}{$\begin{array}{l}\text { Specific surface } \\
\text { area }\end{array}$} & \multicolumn{5}{|c|}{ Pore volumes } \\
\hline & & & $A_{B E T}$ & $\begin{array}{l}S_{2 D-N L D F T} \\
\mathrm{n}^{2} \mathrm{~g}^{-1}\end{array}$ & $V_{0.97}$ & $V_{t}$ & $\begin{array}{l}V_{\text {ultra }} \\
\mathrm{cn}\end{array}$ & $\begin{array}{l}V_{\text {micro }} \\
\mathrm{g}^{-1}\end{array}$ & $V_{\text {meso }}$ \\
\hline PB_700_0.10 & 180 & 30.1 & 552 & 833 & 0.237 & 0.243 & 0.184 & 0.227 & $0.016(6.77 \%)^{\mathbf{c}}$ \\
\hline PB_700_1.00 & 180 & 52.8 & 743 & 1008 & 0.333 & 0.333 & 0.226 & 0.301 & $0.032(9.55 \%)^{\mathbf{c}}$ \\
\hline PB_850_0.10 & 60 & 54.9 & 600 & 818 & 0.263 & 0.266 & 0.169 & 0.240 & $0.026(9.64 \%)^{\mathbf{c}}$ \\
\hline PB_850_1.00 & 30 & 56.7 & 688 & 881 & 0.298 & 0.296 & 0.176 & 0.273 & $0.022(7.57 \%)^{\mathbf{c}}$ \\
\hline PB_775_0.50 & 60 & 43.7 & 719 & 931 & 0.314 & 0.312 & 0.176 & 0.285 & $0.027(8.62 \%)^{\mathbf{c}}$ \\
\hline PB_775_0.50 & 60 & 42.2 & 707 & 936 & 0.309 & 0.306 & 0.171 & 0.282 & $0.025(8.02 \%)^{\mathbf{c}}$ \\
\hline PB_775_0.50 & 60 & 42.4 & 707 & 949 & 0.308 & 0.306 & 0.174 & 0.282 & $0.023(7.64 \%)^{\mathbf{c}}$ \\
\hline PB_650_0.10 ${ }^{d}$ & 60 & 12.5 & 68.8 & 482 & 0.029 & 0.126 & 0.100 & 0.124 & $0.001(1.07 \%)^{\mathbf{c}}$ \\
\hline PB_650_1.00 ${ }^{d}$ & 180 & 25.0 & 447 & 750 & 0.191 & 0.214 & 0.154 & 0.200 & $0.014(6.46 \%)^{\mathbf{c}}$ \\
\hline
\end{tabular}

$359{ }^{c}$ Calculated as $\frac{\text { Vmeso }}{V t} 100$

$360{ }^{d}$ Additional carbons that were not included in the design of experiments.

361 It was clear that a high pressure accelerated carbon gasification, even at $700{ }^{\circ} \mathrm{C}$. At this

362 temperature, an increase in pressure from 0.1 to $1.0 \mathrm{MPa}$ led to a marked increase in the

363 burnout, from $30.1 \%$ to $52.8 \%$, due to the higher reaction rate. In this sense, an increased

$364 \mathrm{CO}_{2}$ partial pressure resulted in a higher fraction of reactant adsorbed on the surface of the

365 sample [42]. These outcomes are in agreement with the study conducted by Malekshahian et

366 al. [42], but disagree with the results reported by Fermoso et al. [43], who observed that

367 gasification of heartwood was enhanced using low partial pressures of $\mathrm{CO}_{2}$. 


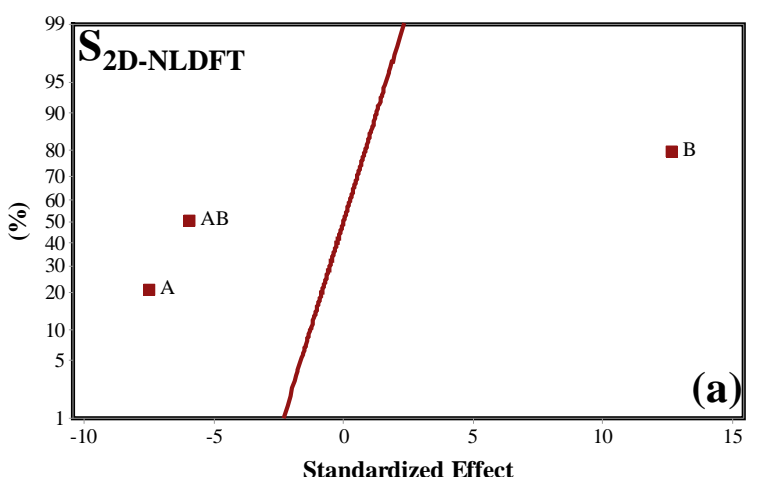

\begin{tabular}{|ll|}
\hline \multicolumn{2}{|c|}{ Effect Type } \\
- Not Significant \\
- & Significant \\
\hline Factor & Name \\
\hline A & Temperature \\
B & Pressure \\
\hline
\end{tabular}
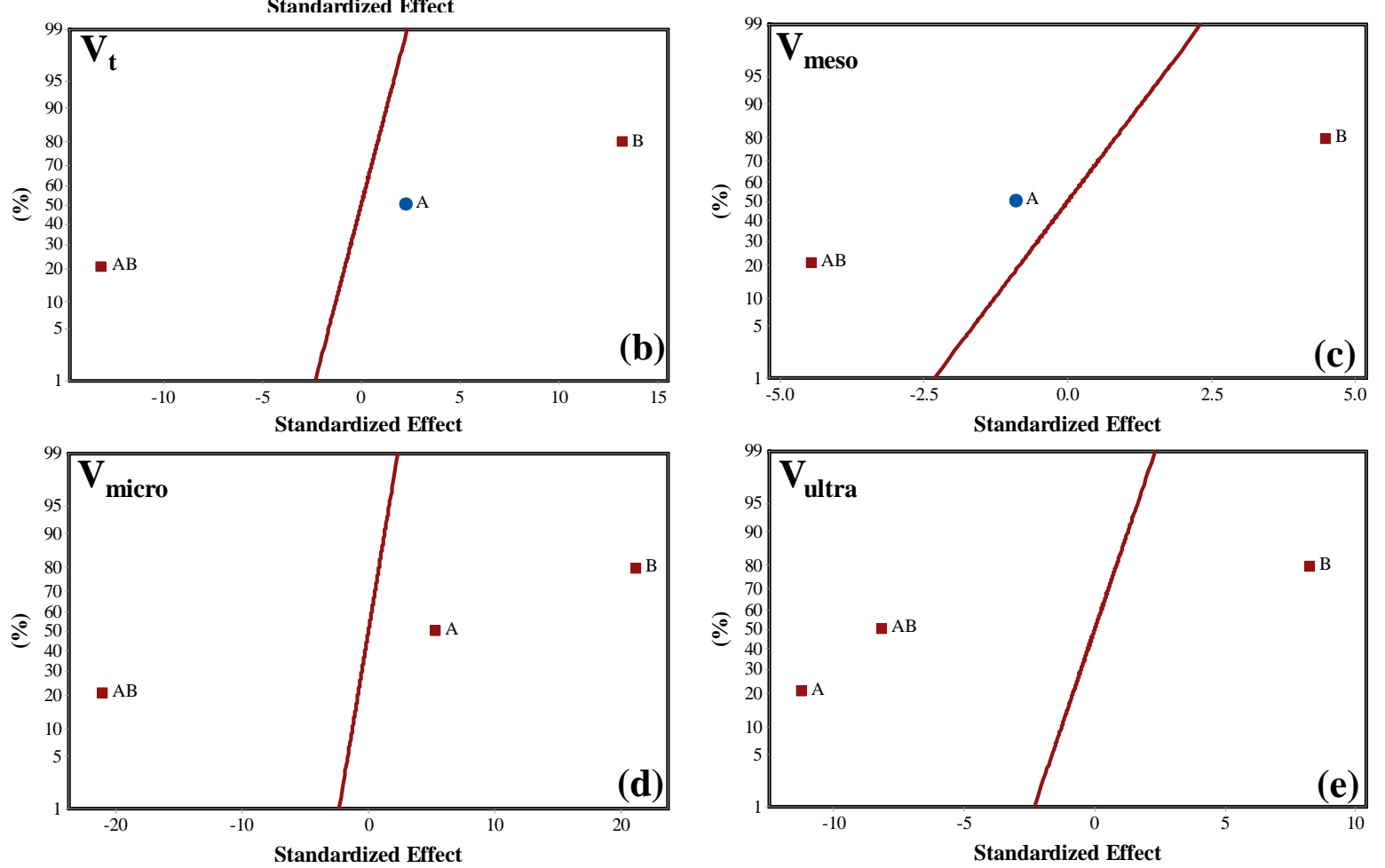

Fig. 2. Normal plots of standardized effects $(\alpha=0.05)$ for physically activated biochars: specific surface area (a); total pore volume (b); mesopore volume (c); micropore volume (d); ultra-micropore volume (e).

The specific surface areas reported in Table 3 were in line with expectations, given the

372 present activation conditions. Even at the lowest temperatures $\left(700^{\circ} \mathrm{C}\right)$ it was possible to

373 obtain relatively high surface areas, even greater than those measured for activated biochars

374 produced at higher temperatures. As can be seen in Fig. 2a, the specific surface area was

375 positively influenced by the absolute pressure and negatively affected by the activation

376 temperature. Especially at 1.0 MPa, relatively low temperatures and longer activation times

377 allowed the biochar to be gasified more homogeneously, thus resulting in a more developed 
porous structure. Conversely, higher temperatures led to faster reaction rates, which can result in a more severe enlargement of micropores and the subsequent loss of surface area. raised from 0.1 to $1.0 \mathrm{MPa}$. In general, the total pore volumes for physically activated 382 biochars, which were not significantly affected by the activation temperature, were higher 383 than those measured for chemically activated carbons. As can be seen when comparing the data reported in Tables 2 and 3, physical activation led to porous carbons with slightly higher ultra-micropore volumes. An inspection of Figs. 2d, 2e and A.3b reveals that high temperatures can lead to some widening of the narrowest micropores, since the activation temperature had a negative effect on the ultra-micropore volumes and a positive one on the micropore volumes. With regards to the volume of mesopores, which was mainly affected by pressure (see Fig. 2c), it should be noticed that physical activation under pressure resulted in more hierarchical porous structures with higher contributions of mesopores (see values of $V_{\text {meso }}$ and relative percentages in Table 3 ). The statistically significant overall curvature terms reported in Table A.3 for $S_{2 D-N L D F T}, V_{t}, V_{\text {meso }}$, and $V_{\text {micro }}$ response variables also suggest that a central composite design could be required for optimization purposes.

394 Given the significant effects of pressure on the textural properties of carbons activated at $700-850{ }^{\circ} \mathrm{C}$, we decided to perform two additional physical activations at $650{ }^{\circ} \mathrm{C}$, leading to the materials called PB_650_0.10 and PB_650_1.00. The results obtained, which are also

397 reported in Table 3, seem to confirm that activation with $\mathrm{CO}_{2}$ under pressure is a very 398 interesting way to produce biomass-derived porous carbons with high specific surface area 399 and wide pore size distributions (including relatively high mesopore volumes), even at 400 relatively low temperatures. 
Due to their relatively high specific surface area, both PB_700_1.00 and CB_3_0.10

404

405 activated biochars (one for each activation procedure) were selected as catalysts and tested during the upgrading process of the aqueous phase of a real pyrolysis oil.

Elemental and moisture analyses of the aqueous phase of the pyrolysis oil revealed that the liquid sample had an average chemical formula of $\mathrm{C}_{5} \mathrm{H}_{6.7} \mathrm{O}_{2}$ and a water content of $80 \mathrm{wt}$. \%. Since the liquid was fed to the reformer without providing additional water, the steam to carbon molar ratio, $\mathrm{S}: \mathrm{C}$, was $4: 1$.

It is generally assumed that deactivation and/or instability of the catalyst can be attributed to two different phenomena: (1) the deposition of carbonaceous material (coke) on the surface of the catalyst, which clogs part of the available active sites; and (2) the extent of gasification reactions (both with steam and $\mathrm{CO}_{2}$ ) of the carbon-based catalyst, which leads to a loss of mass and a subsequent increase in LHSV (i.e., less contact time).

The results obtained in terms of total gas yield, selectivity towards specific gaseous species, hydrogen yield and hydrogen release over time are displayed in Fig. 3a. It should be noted that the poor results measured for the blank test (i.e., empty reactor) suggested that the reactor wall did not play a crucial catalytic role. The physically activated biochar (PB_700_1.00) exhibited performances comparable to those obtained in a previous study [33]. Using this material, which showed a good stability during the whole experiment (see Fig. 3b), a total gas yield of about $40 \%$ was obtained. Nevertheless, its relatively low hydrogen yield indicates that the extent of steam reforming was modest.

Regarding the performance of the chemically activated biochar (CB_3_0.10), a similar total gas yield was measured, compared to the physically activated one. However, selectivity to gaseous products were markedly different, leading to a decrease in the production of $\mathrm{H}_{2}$ (the hydrogen yield was even lower than that of PB_700_1.00) and an increase in that of 

dry reforming, was the main process involved.

429
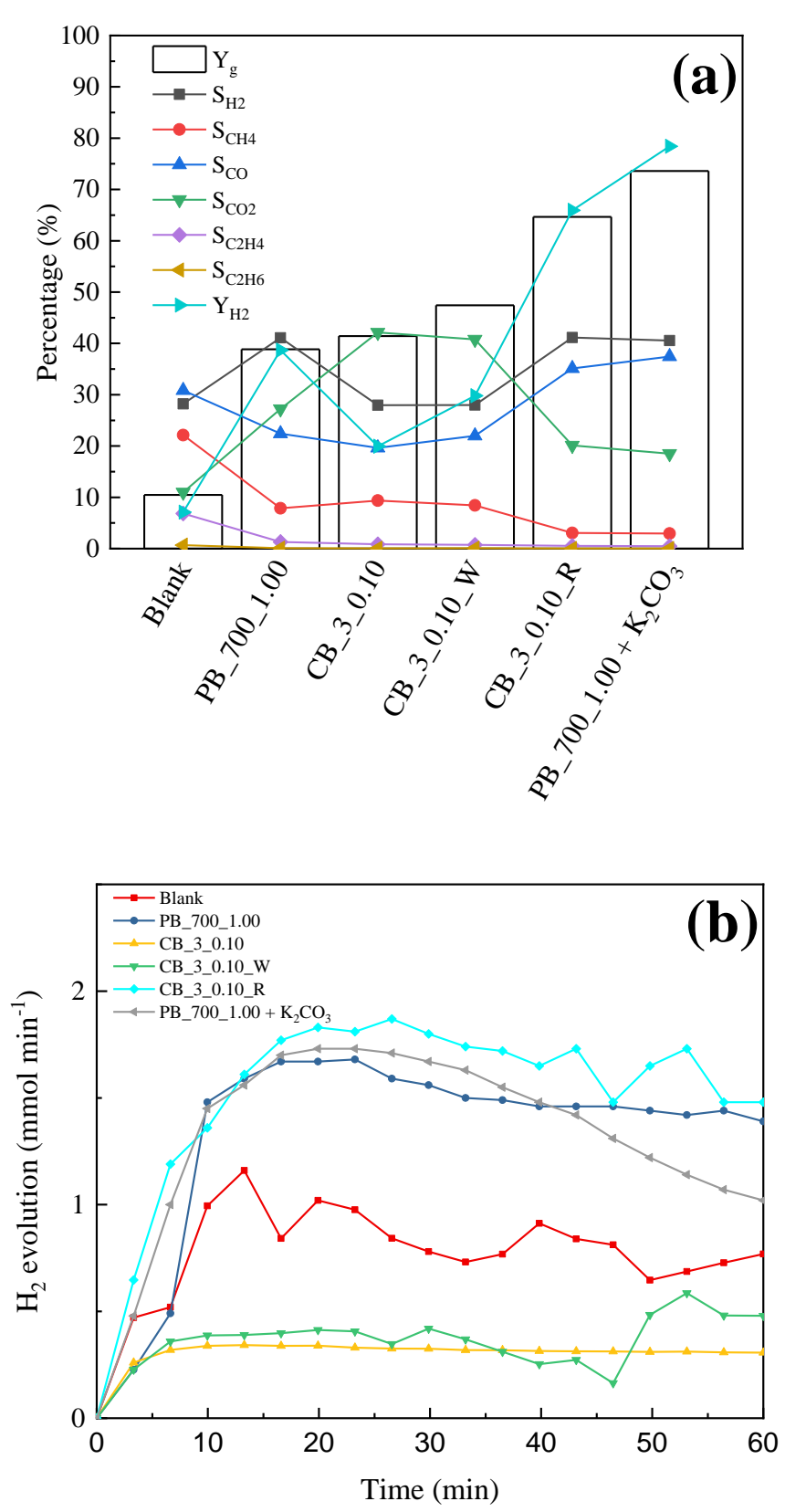

Fig. 3. Results obtained from combined steam and dry reforming of pyrolysis oil at $750^{\circ} \mathrm{C}$ : total and $\mathrm{H}_{2}$ yields ( $Y_{g}$ and $\mathrm{Y}_{\mathrm{H} 2}$, respectively) as well as selectivities toward a given gaseous 433 product, $S_{i}$ (a); and evolution of the hydrogen production rate (b).

434 As can be deduced from Fig. 3a, similar results were also obtained for the chemically 435 activated biochar that was washed with just water (CB_3_0.10_W). The differences in the 
436 performance between the physically and chemically activated biochars could be related to 437 their textural properties. In this respect, the physically activated biochar exhibited a higher 438 specific surface area and higher volumes of micro- and mesopores, thus providing more 439 catalytic active sites of inherent alkali or alkaline earth metal species (AAEMs). The catalytic 440 role of these species (especially $\mathrm{K}, \mathrm{Mg}$ and $\mathrm{Ca}$ ) in both steam reforming and gasification of 441 carbon has been widely reported [25,44-46]. Furthermore, the more hierarchical pore size 442 distribution of PB_700_1.00, with relatively high contributions of the mesopores, could 443 shorten the diffusion path to reach the active sites.

444 Fig. 3b clearly shows that $\mathrm{H}_{2}$ release rates fluctuated over time for most of biochars tested. 445 There are at least two possible explanations for this: First, the coke deposits, which gradually 446 covered the catalyst surface, could have ted to large fluctuations in the extent of the reactions involved. Second, the structural modification of the activated carbons (the process temperature was higher than the activation temperature) could also led to unsteady hydrogen flow rates at the outlet. It should be noted that the reaction system studied was certainly 450 complex, due the numerous competitive reactions that can affect the yields of the different gaseous products. Nevertheless, it can be assumed that methane is mainly produced by the cracking of the heaviest fraction of the pyrolysis oil, and that its yield will be correlated to the amount of coke produced [47]. Similarly, Fig. 3a reveals that the selectivity towards methane was almost constant for PB_700_1.00, CB_3_0.10, and CB_3_0.10_W materials. Therefore, it can be concluded that the coke production in the process was quite similar for the abovementioned carbons, suggesting that some structural modifications in the carbons could be accounted for the unsteady production of hydrogen. These modifications could be ascribed to the reverse Boudouard reaction $[48,49]$, steam gasification and, in the case of the chemical activated biochars, potassium-catalyzed gasification. To support this argument, Fig. 4 shows

460 the textural properties of fresh and spent activated biochars. Contrary to the loss of porosity 
461 observed for spent PB_700_1.00 and CB_3_0.10 catalysts, the spent CB_3_0.1_W material 462 showed an increase in pore volumes, especially for micropores. In addition, the results from 463 TPD measurements, which are summarized graphically in Figs. 5 and A.6, indicate that the 464 water-washed chemically activated carbon exhibited a larger mass loss (with an increased 465 release of $\mathrm{CO}_{2}$ and $\mathrm{CO}$, as shown in Fig. A.6) than that of the acid-washed carbon, thus 466 confirming a greater extent of carbon gasification. This fact could be attributed to the residual 467 amount of activation reagent available on the surface of the catalyst CB_3_0.10_W, which might promote further biochar gasification during the experiment, as recently reported by Wang et al. [11].

To understand better the effect of the washing procedure on the performance of chemically activated biochars, an unwashed (raw) material (CB_3_0.10_R) was also tested as catalyst. In this case, the total gas yield was $65 \%$ with enhanced selectivity towards both $\mathrm{H}_{2}$ and $\mathrm{CO}$ (see Fig. 3a), thus indicating a higher extent of the steam reforming reactions (leading to a $Y_{H 2}$ of $66 \%$ ). Fig. 6 displays the FTIR spectra obtained for fresh and spent chemically activated biochars as well as for pure $\mathrm{K}_{2} \mathrm{CO}_{3}$. In the case of acid and waterwashed samples, no evident $\mathrm{K}_{2} \mathrm{CO}_{3}$ content was detected on the surface, indicating the effectiveness of both washing procedures. On the other hand, most of the chemical activating agent available on the surface of the fresh $C B \_3 \_0.10 \_R$ catalyst disappeared after the catalytic test. The potassium carbonate (and other chemical species derived from its partial 480 decomposition) available on the surface of the catalyst at the beginning of the reforming test 481 (reductive environment) could progressively be reduced to metallic potassium $\left(\mathrm{K}^{0}\right)$, leading to a further promotion of reforming reactions. Furthermore, a process temperature relatively close to the volatilization point of potassium can enhance the mobility and reactivity of the metal [50]. Generally speaking, activated biochars have relatively abundant oxygen and nitrogen-containing functional groups, which are not present in the materials shown in Fig. 6. 
486 The reason behind this could be the relatively high activation temperatures, since the majority 487 of functional groups decompose below $800{ }^{\circ} \mathrm{C}$ [51]. Furthermore, the relatively high amount 488 of $\mathrm{K}_{2} \mathrm{CO}_{3}$ loaded on the analyzed samples resulted in a very large peak, which may hide other 489 peaks of interest, such as those related to oxygenated functionalities.

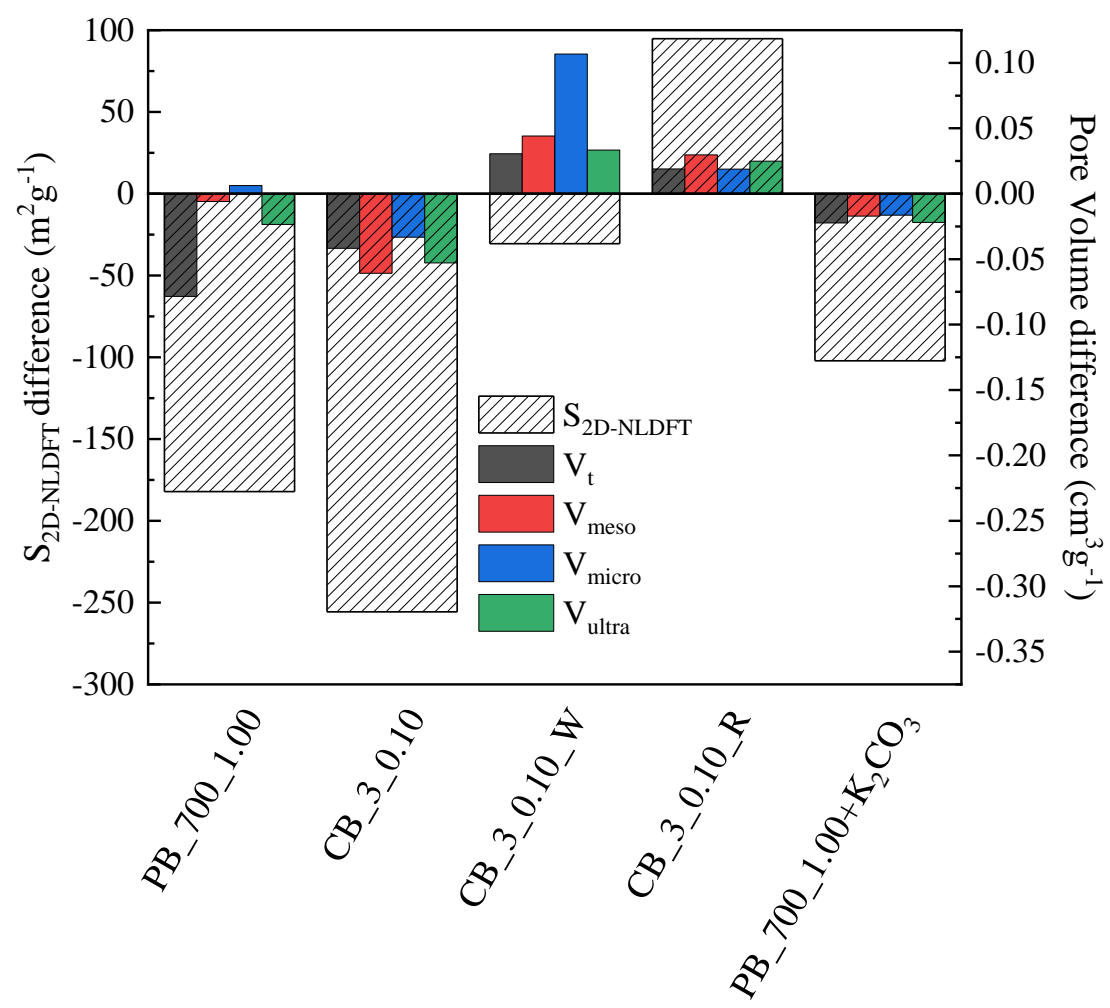

490

491 Fig. 4. Differences in textural properties between the fresh and spent activated biochars used 492 as catalysts in steam and dry reforming tests. 


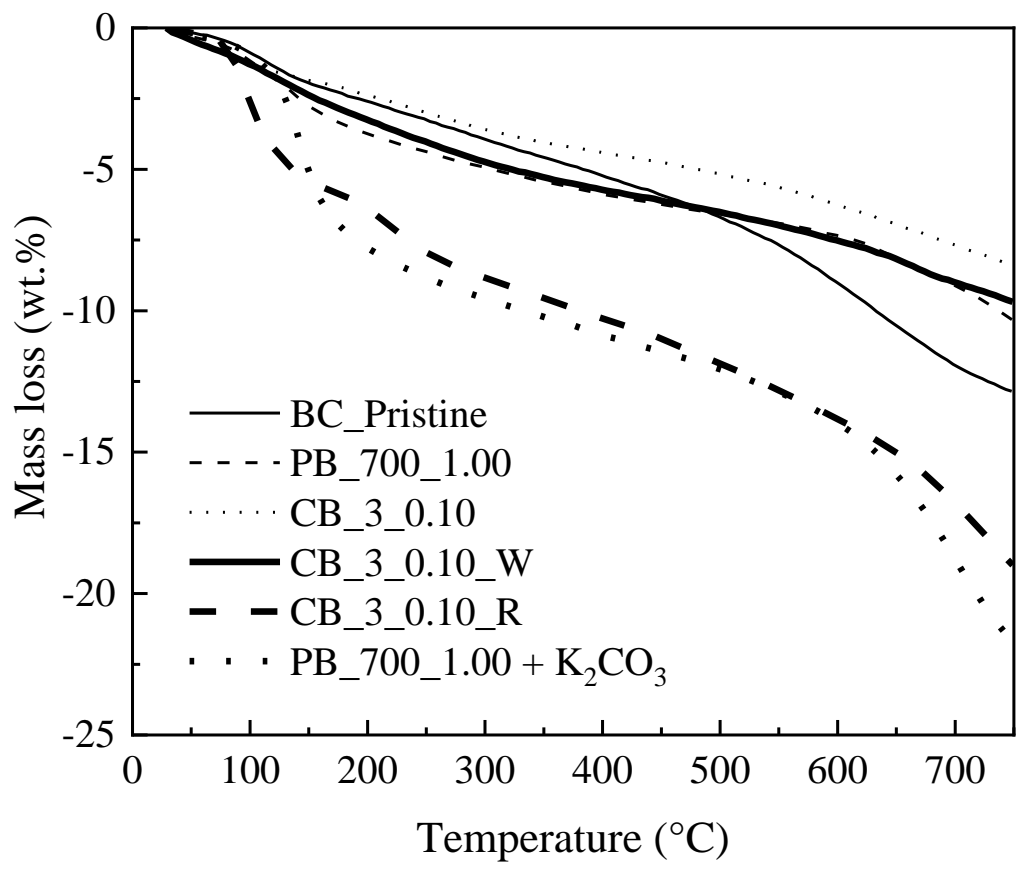

495 Fig. 5. Results from TPD characterization (percentage of mass loss vs. temperature) for 496 pristine and activated biochars.

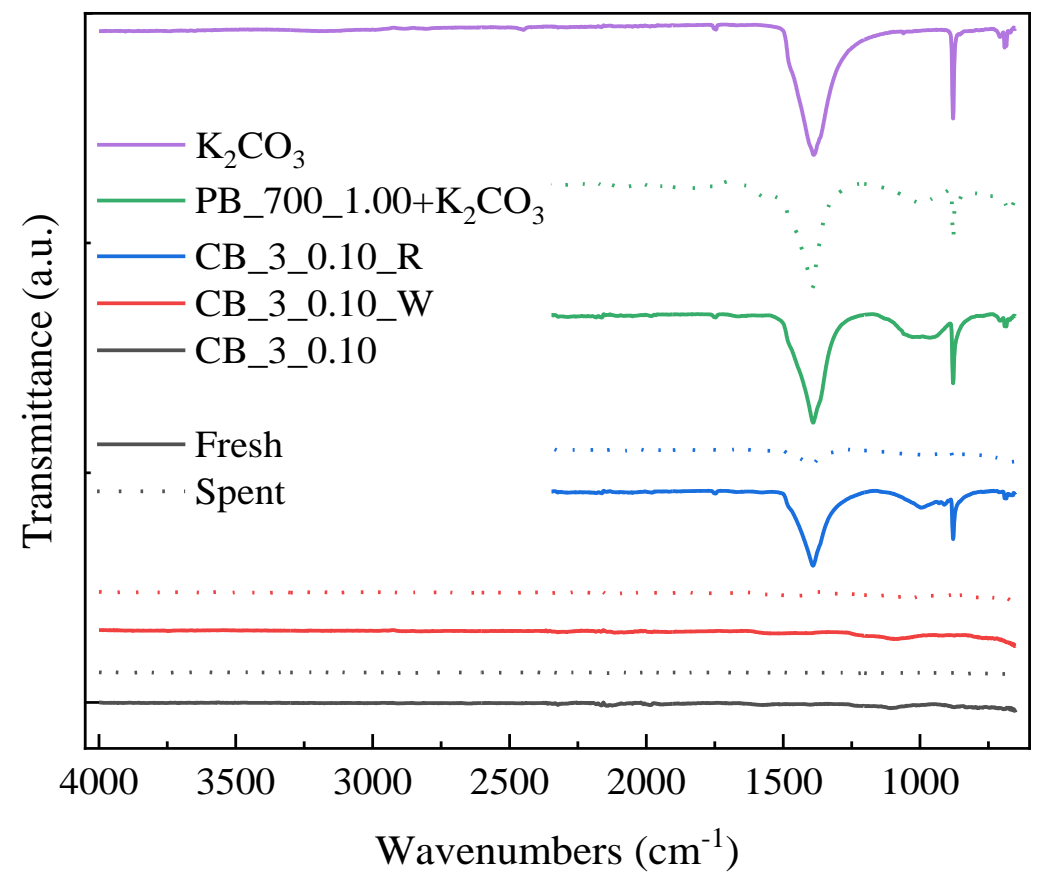

498 Fig. 6. Comparison of the FTIR spectra obtained for pure $\mathrm{K}_{2} \mathrm{CO}_{3}$ and some activated biochars 499 tested in the present study. 
The results from TPD measurements (see Fig. 5) showed that the mass loss under an inert atmosphere was much higher for the unwashed catalyst. In addition, the release of $\mathrm{CO}$ during TPD also increased for the material CB_3_0.10_R (see Fig. A.6c). The increase in both mass loss and $\mathrm{CO}$ production when heating in $\mathrm{N}_{2}$ up to $750{ }^{\circ} \mathrm{C}$ could be due to the reaction of

$504 \mathrm{~K}_{2} \mathrm{CO}_{3}$ with carbon, which results in an additional release of $\mathrm{CO}$, especially at temperatures 505 near $700{ }^{\circ} \mathrm{C}$ and above, and the formation of catalytically active $\mathrm{COK}$ and $\mathrm{CK}$ complexes 506 [52]. Hence, a certain gasification of carbon during the catalytic upgrading tests should be 507 expected. In line with this, Fig.4 shows that the spent CB_3_0.10_R exhibited more 508 developed textural properties than the fresh one (for instance, the specific surface area 509 increased from $29 \mathrm{~m}^{2} \mathrm{~g}^{-1}$ to $124 \mathrm{~m}^{2} \mathrm{~g}^{-1}$ ), thus confirming the extent of gasification reactions.

510 Despite the loss of catalyst through carbon gasification, which results in a higher LHSV, the 511 production rate of $\mathrm{H}_{2}$ for this catalyst was relatively stable during the experiment. This could

512 be explained by the fact that the carbon gasification catalyzed by $\mathrm{K}_{2} \mathrm{CO}_{3}$ contributes to 513 creating new pores and then counterbalancing the deposition of coke, which induces 514 micropore blockage and active sites coverage.

515 Based on the findings discussed above, it seems reasonable to assume that an activated 516 biochar having a wider hierarchical pore size distribution and some availability of $\mathrm{K}_{2} \mathrm{CO}_{3}$ on 517 its surface appears as an excellent candidate for catalytic pyrolysis vapors upgrading. With 518 this in mind, a new biochar-derived material, designated as $\mathrm{PB} \_700 \_1.00+\mathrm{K}_{2} \mathrm{CO}_{3}$, was 519 prepared by impregnating the material PB_700_1.00 with $\mathrm{K}_{2} \mathrm{CO}_{3}$ at a mass ratio of carbonate 520 to precursor of $3: 1$. It should be expected that the better textural properties of the starting 521 physically activated biochar could lead to a more homogeneous dispersion of the active phase on the carbon support, thus resulting in an improved performance of the catalyst. 
reported in the present study (78\%). From the FTIR spectra given in Fig. 6, it can be seen that a fraction of $\mathrm{K}_{2} \mathrm{CO}_{3}$ was still present on the catalyst surface after running the test.

XPS analyses were carried out for both PB_700_1.00 and PB_700_1.00+ $\mathrm{K}_{2} \mathrm{CO}_{3}$ materials to get additional insight into the role of $\mathrm{K}_{2} \mathrm{CO}_{3}$ during the pyrolysis vapors upgrading process. From the summarized XPS results given in Table 4, it can be observed that the atomic composition of PB_700_1.00 remained relatively constant after the catalytic test, even though the simultaneous increase of the peaks related to CII and OII seemed to indicate the formation of phenolic groups on the catalysts. The comparison of the atomic compositions between the fresh and spent PB_700_1.00+ $\mathrm{K}_{2} \mathrm{CO}_{3}$ materials indicates that the extent of carbon gasification reactions was much higher than that of the PB_700_1.00 material. Furthermore, from the spectra displayed in Fig. A.7, an additional peak at $283 \mathrm{eV}$, which is attributed to $\mathrm{KC}_{\mathrm{x}}$ carbides, was observed for the spent PB_700_1.00+K $\mathrm{K}_{2} \mathrm{CO}_{3}$. On the other hand, the $\mathrm{K} 2 \mathrm{p} 3 / 2$ region presented only a contribution and suggested the presence of potassium on the surface as $\mathrm{K}_{2} \mathrm{O}$ or $\mathrm{K}_{2} \mathrm{O}_{2}$, according to Li et al.[53]. This fact was also confirmed by the shift to lower binding energies of the OII and OIII peaks (see Fig. A.7). The marked difference in the potassium content between fresh and spent PB_700_1.00+ $\mathrm{K}_{2} \mathrm{CO}_{3}$ was probably due to the migration of the potassium-based compounds from the internal pores to the external surface, which can lead to the formation of a coating layer composed of $\mathrm{K}_{2} \mathrm{O}$, as confirmed by SEM-EDX images reported in Fig. 7. The presence of potassium oxides on

544 the surface of the catalyst can be ascribed to $(i)$ the direct decomposition of the carbonate 545 (Reaction 7) and/or (ii) the formation of metallic potassium. The latter can migrate from the 546 inner structure of the catalyst to its surface during the course of the pyrolysis vapors 547 upgrading tests and finally be oxidized when the catalyst has been removed from the reactor. 548 This fact can also justify the significant decrease in the specific surface area reported in Fig. 4 549 for the spent PB_700_1.00+K $\mathrm{K}_{2} \mathrm{CO}_{3}$ catalyst (from 130 to $27.7 \mathrm{~m}^{2} \mathrm{~g}^{-1}$ ). 
551 dispersion of $\mathrm{K}_{2} \mathrm{CO}_{3}$ was achieved for the fresh catalyst. Nevertheless, both fresh and spent

552 catalysts exhibited some clusters and snail shell-like agglomerates, which could be attributed

553 to the relatively high load of carbonate. However, no visible surface carbon layers was found

554 on the superficial $\mathrm{K}_{2} \mathrm{O}$ of the spent catalyst, thus suggesting that the extent of the carbon

555 gasification was probably sufficient to prevent the deposition of coke on the surface.

556 Table 4. Surface composition measured by XPS and peak contributions of C1s, O1s and K2p.

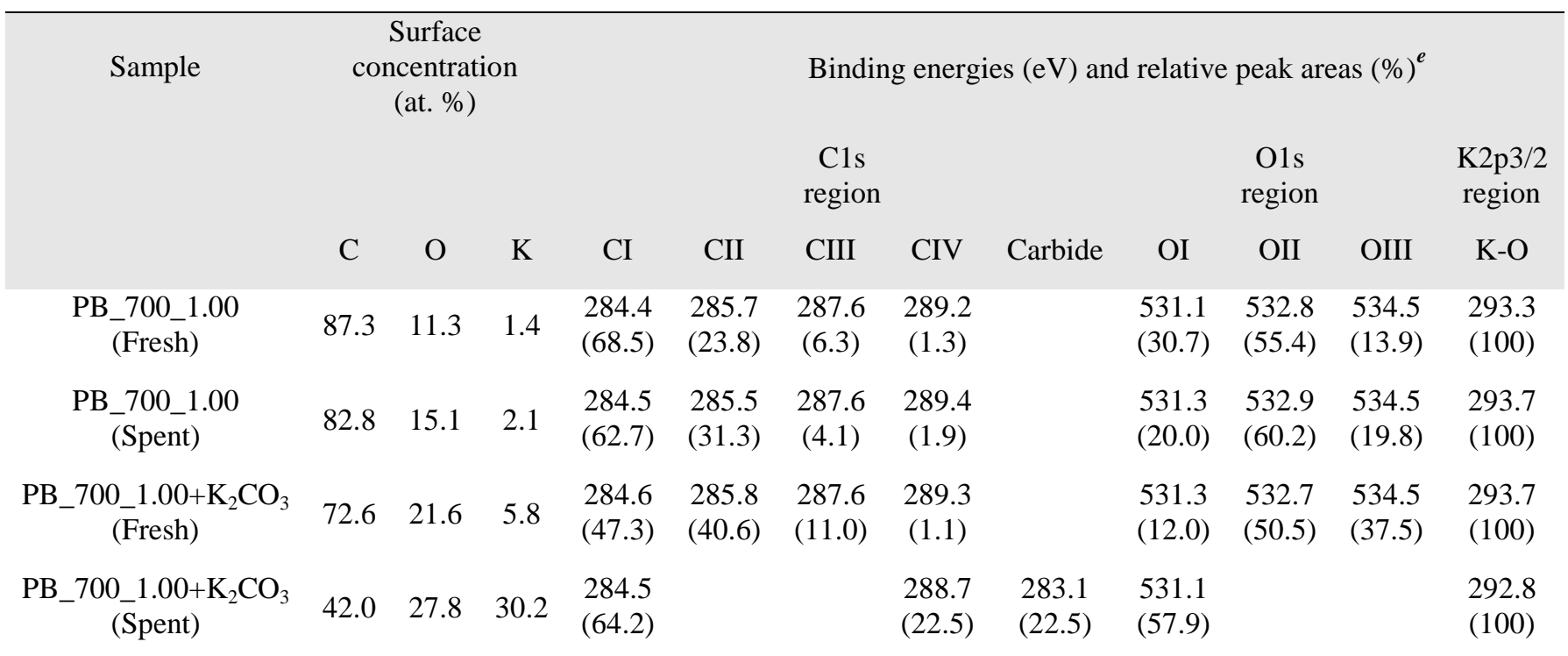

${ }^{e} \mathrm{C} 1 \mathrm{~s}$ binding energies in carbon materials: CI, hydrocarbons, aromatics, aliphatics (284.5 eV); CII, single bond $\mathrm{C}-\mathrm{O}$ associated to alcohols, phenols, carboxyls $(286 \mathrm{eV})$; CIII, double bond $\mathrm{C}=\mathrm{O}$ in carbonyl, quinone (287.5 $\mathrm{eV})$; CIV, carboxyl and carbonate groups $(288.7 \mathrm{eV})$. O1s binding energies in carbon materials: OI, $\mathrm{C}=\mathrm{O}$ quinone type groups (around $531 \mathrm{eV}$ ); $\mathbf{O I I}, \mathrm{C}-\mathrm{OH}$ phenol

562 groups and/or C-O-C ether groups (532.5 eV), OIII, chemisorbed oxygen (COOH carboxylic groups) and/or

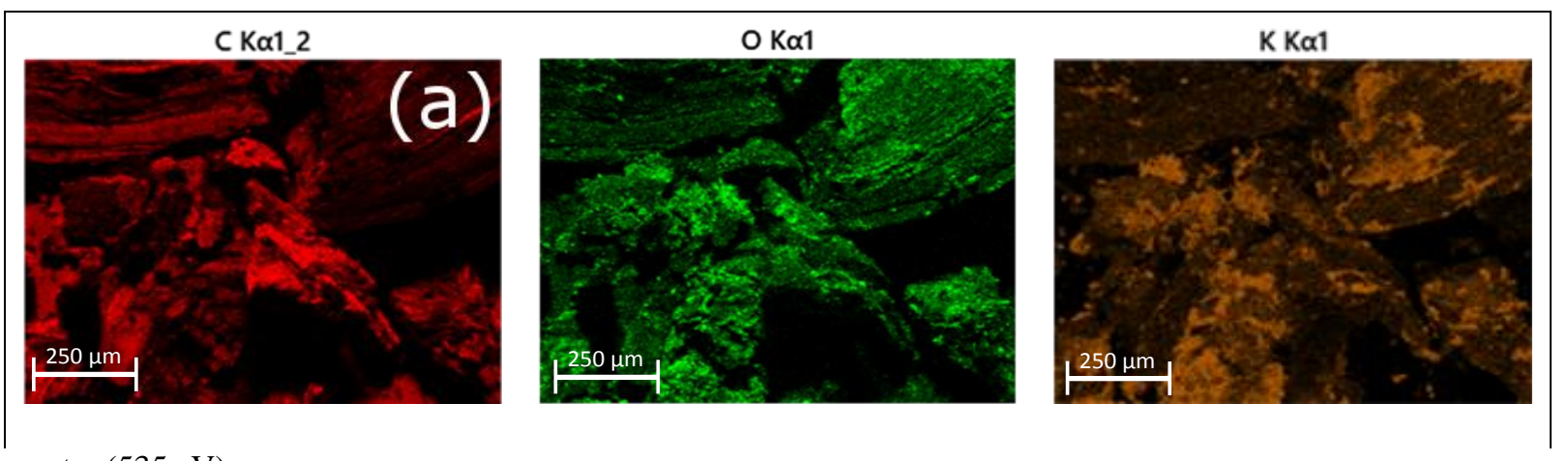

water $(535 \mathrm{eV})$. 

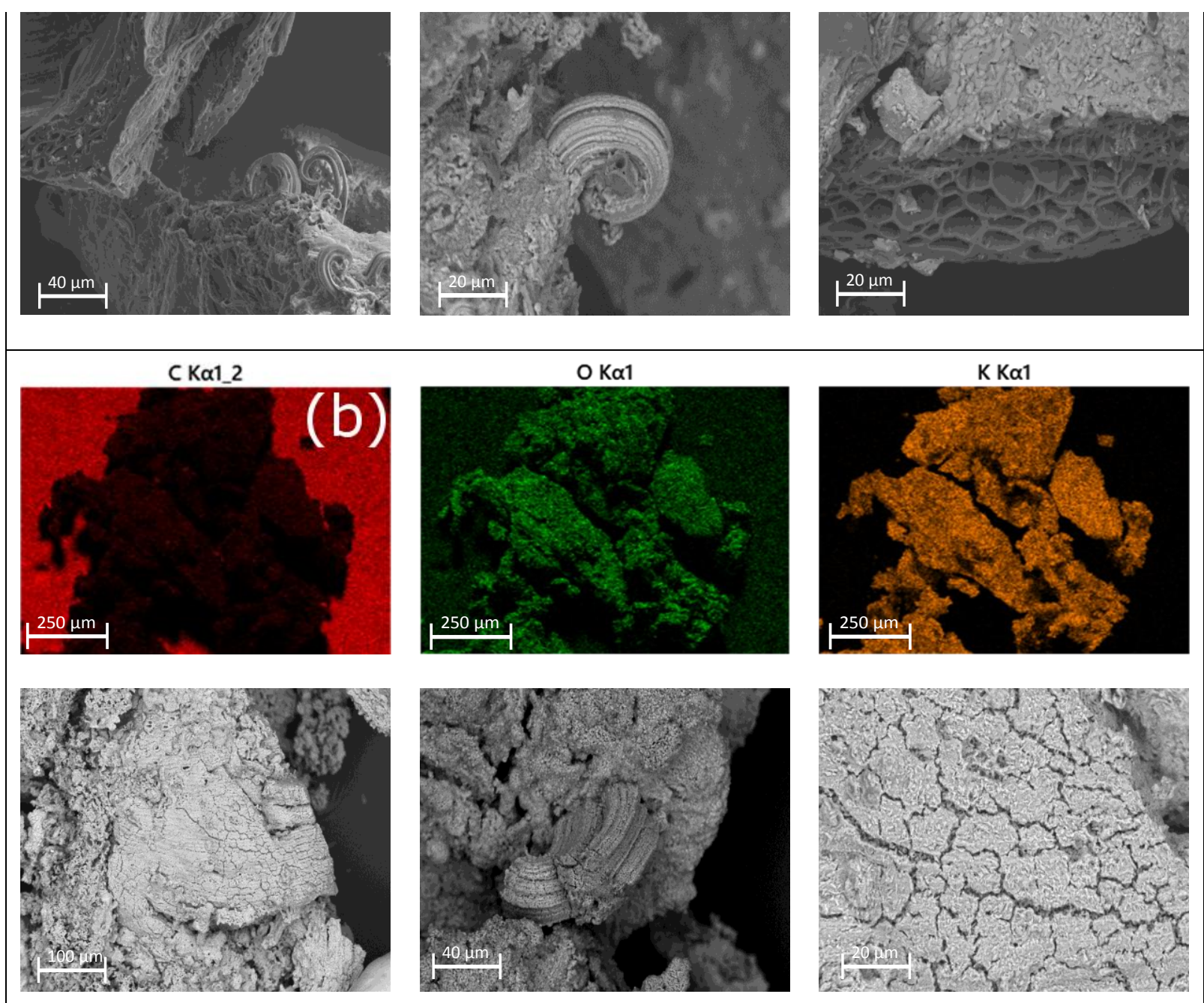

564 Fig. 7. SEM-EDX images of fresh (a) and spent (b) $\mathrm{PB}_{-} 700 \_1.00+\mathrm{K}_{2} \mathrm{CO}_{3}$ catalyst.

\section{Conclusions}

From the results obtained in this study, the following conclusions can be drawn:

1. The chemical activation of the pristine biochar led to carbonaceous solids with a relatively high specific surface area and well-developed microporous structure. The most important activation parameter was found to be the amount of activation agent, which accounted for the development of the porous structure. Activation pressure, on the other hand, was not significant for the outcomes of the procedure. Regarding the washing efficiency, acid washing resulted to be effective in cleaning the surface of the samples, whereas washing with water was not 
sufficient to remove completely the residual reactants, partially clogging the porosity of the samples.

2. Physical activation was found to be more sensitive to the process parameters. It was possible to obtain acceptable values of specific surface area even at low temperature $\left(650{ }^{\circ} \mathrm{C}\right)$ by increasing the activation pressure to $1.00 \mathrm{MPa}$. A negative effect of the activation temperature on the results was also observed. In fact, the surface area decreased with the increase in the activation temperature, probably due to the widening of the smaller pores by a too rapid (and thus less controlled) gasification.

3. The most promising material produced by physical or chemical activation (PB_700_1.00 and CB_3_0.10) were tested as catalysts in the upgrading of the aqueous fraction of a real pyrolysis oil. Both activated biochars, which were initially characterized by a well-developed porosity, did not exhibit good performance, showing a huge decrease in the specific surface area, probably due to coke deposition. Nevertheless, the addition of $\mathrm{K}_{2} \mathrm{CO}_{3}$ to the best physically activated biochar boosted the overall performance towards the production of more hydrogen, as a consequence of the enhanced reforming of pyrolysis oil. This finding can be related to the availability of $\mathrm{K}^{0}$, which was formed from the decomposition of the $\mathrm{K}_{2} \mathrm{CO}_{3}$ previously deposited on the activated biochar. 


\section{Acknowledgments}

595 This project received funding from the European Union's Horizon 2020 research and 596 innovation programme under the Marie Skłodowska-Curie grant agreement No 721991. The 597 authors also acknowledge the funding from the Aragón Government (Ref. T22_20R), co598 funded by FEDER 2014-2020 "Construyendo Europa desde Aragón". ". This study was 599 partly supported by the French PIA project "Lorraine Université d'Excellence", reference 600 ANR-15-IDEX-04-LUE, PROMOTEE project and TALiSMAN project, funded by FEDER 601 (2019-000214). The authors gratefully thank José Antonio Manso (UNIZAR) and Philippe 602 Gadonneix (IJL) for their help in the preparation and characterization of the samples and 603 Sandrine Mathieu (IJL) for the SEM characterization.

\section{Appendix A. Supplementary data}

605 Further details on characterization of pristine and activated biochars. Statistical outcomes 606 from the adopted designs of experiments.

\section{Nomenclature}

608

$$
A_{B E T} \quad \text { Brunauer-Emmett-Teller area }\left(\mathrm{m}^{2} \mathrm{~g}^{-1}\right)
$$

609

$d_{p} \quad$ Pore diameter $(\mathrm{nm})$

610

$F_{B O}$

Molar flow rate of dry bio oil $\left(\mathrm{mol} \mathrm{min}^{-1}\right)$

$611 \quad F_{H 2 A v} \quad$ Experimental average $\mathrm{H}_{2}$ molar flow rate $\left(\mathrm{mol} \mathrm{min} \mathrm{m}^{-1}\right)$

$612 \quad F_{H 2 \text { Stoi }} \quad \mathrm{H}_{2}$ stoichiometric molar flow rate $\left(\mathrm{mol} \mathrm{min}{ }^{-1}\right)$

$613 \quad m_{0} \quad$ Initial mass of biochar before activation $(\mathrm{g})$

$614 \quad m_{c} \quad$ Biochar mass before the washing step (g)

$615 \quad m_{f} \quad$ Final mass of biochar after activation $(\mathrm{g})$ 
$616 \quad m_{g} \quad$ Total mass of produced gas during the upgrading process $(\mathrm{g})$

$617 \quad m_{l} \quad$ Mass of liquid fed into the upgrading reactor $(\mathrm{g})$

$618 \quad m_{w} \quad$ Biochar mass after the washing step $(\mathrm{g})$

$619 \quad n_{i} \quad$ Produced amount of a given gaseous specie i (mol)

$620 \quad n_{\text {tot }} \quad$ Total amount of produced gas (mol)

$621 S_{2 D-N L D F T} \quad$ 2D-NLDFT specific surface area $\left(\mathrm{m}^{2} \mathrm{~g}^{-1}\right)$

$622 \quad S_{i} \quad$ Selectivity toward a given gaseous specie $i(\%)$

$623 \quad V_{0.97} \quad$ Gurvitch pore volume $\left(\mathrm{cm}^{3} \mathrm{~g}^{-1}\right)$

$624 \quad V_{\text {meso }} \quad$ Volume of mesopores $\left(\mathrm{cm}^{3} \mathrm{~g}^{-1}\right)$

$625 \quad V_{\text {micro }} \quad$ Volume of micropores $\left(\mathrm{cm}^{3} \mathrm{~g}^{-1}\right)$

$626 \quad V_{t} \quad$ Total pore volume $\left(\mathrm{cm}^{3} \mathrm{~g}^{-1}\right)$

$627 \quad V_{\text {ultra }} \quad$ Volume of ultra-micropores $\left(\mathrm{cm}^{3} \mathrm{~g}^{-1}\right)$

$628 \quad Y_{g} \quad$ Total gas yield (\%)

$629 \quad Y_{H 2} \quad$ Hydrogen yield $(\%)$

$630 \quad Y_{\text {wash }} \quad$ Washing yield (\%)

$631 \quad \eta \quad$ Degree of burnout $(\%)$

632 Acronyms

633 FTIR Fourier-Transform Infrared spectroscopy

634 GHSV Gas hourly space velocity

635 LHSV Liquid hourly space velocity 
$636 \quad$ PSD $\quad$ Pore size distribution

637 RSM Response surface methodology

$638 \quad$ S:C $\quad$ Steam to carbon molar ratio

639 STP Standard temperature and pressure

640 TPD Temperature-programmed desorption

641 XPS X-ray photoelectron spectroscopy

$642 \mu-\mathrm{GC} \quad$ Micro gas chromatograph

643 
[1] Guedidi H, Lakehal I, Reinert L, Lévêque JM, Bellakhal N, Duclaux L. Removal of ionic liquids and ibuprofen by adsorption on a microporous activated carbon: Kinetics, isotherms, and pore sites. Arab J Chem 2020;13:258-70.

648 https://doi.org/10.1016/j.arabjc.2017.04.006.

[2] Santoyo-Cisneros R, Rangel-Mendez JR, Nava JL, Larios-Durán ER, Chazaro-Ruiz LF. Influence of surface chemistry of activated carbon electrodes on electro-assisted adsorption of arsenate. J Hazard Mater 2020;392:122349.

[3] Acharya SP, Johnson J, Weidhaas J. Adsorption kinetics of the herbicide safeners, benoxacor and furilazole, to activated carbon and agricultural soils. J Environ Sci (China) 2020;89:23-34. https://doi.org/10.1016/j.jes.2019.09.022.

[4] Palomo J, Rodríguez-Cano MA, Rodríguez-Mirasol J, Cordero T. On the kinetics of methanol dehydration to dimethyl ether on Zr-loaded P-containing mesoporous activated carbon catalyst. Chem Eng J 2019;378:122198. https://doi.org/10.1016/j.cej.2019.122198. 2019;258:116138. https://doi.org/10.1016/j.fuel.2019.116138.

666

[7] Li H, Zheng F, Wang J, Zhou J, Huang X, Chen L, et al. Facile preparation of zeolite667 activated carbon composite from coal gangue with enhanced adsorption performance. Chem Eng J 2020;390:124513. https://doi.org/10.1016/j.cej.2020.124513. 
[8] Ding S, Liu Y. Adsorption of CO2 from flue gas by novel seaweed-based $\mathrm{KOH}-$ activated porous biochars. Fuel 2020;260:116382. https://doi.org/10.1016/j.fuel.2019.116382.

[9] Iriarte-Velasco U, Sierra I, Zudaire L, Ayastuy JL. Preparation of a porous biochar from the acid activation of pork bones. Food Bioprod Process 2016;98:341-53. https://doi.org/10.1016/j.fbp.2016.03.003.

[10] Sayğglı H, Akkaya Sayğglı G. Optimized preparation for bimodal porous carbon from lentil processing waste by microwave-assisted K2 CO3 activation : Spectroscopic characterization and dye decolorization activity. J Clean Prod 2019;226:968-76. https://doi.org/10.1016/j.jclepro.2019.04.121.

[11] Wang L, Sun F, Hao F, Qu Z, Gao J, Liu M, et al. A green trace K2CO3 induced catalytic activation strategy for developing coal-converted activated carbon as advanced candidate for $\mathrm{CO} 2$ adsorption and supercapacitors. Chem Eng J 2020;383:123205. https://doi.org/10.1016/j.cej.2019.123205.

[12] Mai TT, Vu DL, Huynh DC, Wu NL, Le AT. Cost-effective porous carbon materials synthesized by carbonizing rice husk and $\mathrm{K} 2 \mathrm{CO} 3$ activation and their application for lithium-sulfur batteries. J Sci Adv Mater Devices 2019;4:223-9. https://doi.org/10.1016/j.jsamd.2019.04.009.

[13] Lahijani P, Zainal ZA, Mohammadi M, Mohamed AR. Conversion of the greenhouse gas $\mathrm{CO} 2$ to the fuel gas $\mathrm{CO}$ via the Boudouard reaction: A review. Renew Sustain Energy Rev 2015;41:615-32. https://doi.org/10.1016/j.rser.2014.08.034.

[14] Şahin Ö, Saka C. Preparation and characterization of activated carbon from acorn shell by physical activation with $\mathrm{H} 2 \mathrm{O}-\mathrm{CO} 2$ in two-step pretreatment. Bioresour Technol 2013;136:163-8. https://doi.org/10.1016/j.biortech.2013.02.074.

[15] Guo Y, Tan C, Sun J, Li W, Zhang J, Zhao C. Porous activated carbons derived from 
waste sugarcane bagasse for CO2 adsorption. Chem Eng J 2020;381:122736. https://doi.org/10.1016/j.cej.2019.122736.

696

[16] Bertero M, Puente G De, Sedran U. Fuels from bio-oils : Bio-oil production from different residual sources, characterization and thermal conditioning. Fuel 2012;95:263-71. https://doi.org/10.1016/j.fuel.2011.08.041.

[17] Fu M, Qi W, Xu Q, Zhang S, Yan Y. Hydrogen production from bio-oil model compounds dry ( $\mathrm{CO} 2$ ) reforming over Ni/A12O3 catalyst. Int J Hydrogen Energy 2015;41:1494-501. https://doi.org/10.1016/j.ijhydene.2015.11.104.

[18] Santamaria L, Artetxe M, Lopez G, Cortazar M, Amutio M, Bilbao J, et al. Effect of $\mathrm{CeO} 2$ and $\mathrm{MgO}$ promoters on the performance of a $\mathrm{Ni} / \mathrm{Al} 2 \mathrm{O} 3$ catalyst in the steam reforming of biomass pyrolysis volatiles. Fuel Process Technol 2020;198:106223. https://doi.org/10.1016/j.fuproc.2019.106223.

[19] Santamaria L, Lopez G, Arregi A, Amutio M, Artetxe M, Bilbao J, et al. Stability of different $\mathrm{Ni}$ supported catalysts in the in-line steam reforming of biomass fast pyrolysis volatiles. Appl Catal B Environ 2019;242:109-20. https://doi.org/10.1016/j.apcatb.2018.09.081.

[20] Bimbela F, Ábrego J, Puerta R, García L, Arauzo J. Catalytic steam reforming of the aqueous fraction of bio-oil using Ni-Ce / Mg-Al catalysts. Appl Catal B Environ 2017;209:346-57. https://doi.org/10.1016/j.apcatb.2017.03.009.

[21] Phongprueksathat N, Meeyoo V, Rirksomboon T. Steam reforming of acetic acid for hydrogenproduction : Catalytic performances of Ni and Co supported on Ce0 $75 \mathrm{Zr} 0 \cdot 25 \mathrm{O} 2$ catalysts. Int J Hydrogen Energy 2019;44:9359-67. https://doi.org/10.1016/j.ijhydene.2019.02.085.

[22] Domine ME, Iojoiu EE, Davidian T, Guilhaume N, Mirodatos C. Hydrogen production from biomass-derived oil over monolithic Pt- and Rh-based catalysts using steam 
reforming and sequential cracking processes. Catal Today 2008;133-135:565-73. https://doi.org/10.1016/j.cattod.2007.12.062.

721

722

723

724

725

726

727

728

729

730

731

732

733

734

735

736

737

738

739

740

741

742

743

[23] Li X, Zhang Z, Zhang L, Fan H, Li X, Liu Q, et al. Investigation of coking behaviors of model compounds in bio-oil during steam reforming. Fuel 2020;265:116961. https://doi.org/10.1016/j.fuel.2019.116961.

[24] Ma Z, Xiao R, Zhang H. Catalytic steam reforming of bio-oil model compounds for hydrogen-rich gas production using bio-char as catalyst. Int J Hydrogen Energy 2016;42:3579-85. https://doi.org/10.1016/j.ijhydene.2016.11.107.

[25] Feng D, Zhao Y, Zhang Y, Sun S, Meng S, Guo Y, et al. Effects of K and Ca on reforming of model tar compounds with pyrolysis biochars under $\mathrm{H} 2 \mathrm{O}$ or $\mathrm{CO} 2$. Chem Eng J 2016;306:422-32. https://doi.org/10.1016/j.cej.2016.07.065.

[26] Buentello-Montoya D, Zhang X, Li J, Ranade V, Marques S, Geron M. Performance of biochar as a catalyst for tar steam reforming: Effect of the porous structure. Appl Energy 2020;259:114176. https://doi.org/10.1016/j.apenergy.2019.114176.

[27] Feng D, Zhao Y, Zhang Y, Zhang Z, Sun S. Roles and fates of K and Ca species on biochar structure during in-situ tar $\mathrm{H} 2 \mathrm{O}$ reforming over nascent biochar. Int J Hydrogen Energy 2017;42:21686-96. https://doi.org/10.1016/j.ijhydene.2017.07.096.

[28] Zhang Z, Ou Z, Qin C, Ran J, Wu C. Roles of alkali/alkaline earth metals in steam reforming of biomass tar for hydrogen production over perovskite supported $\mathrm{Ni}$ catalysts. Fuel 2019;257:116032. https://doi.org/10.1016/j.fuel.2019.116032.

[29] Megaritis A, Zhuo Y, Messenböck R, Dugwell DR, Kandiyoti R. Pyrolysis and gasification in a bench-scale high-pressure fluidized-bed reactor. Energy Fuels 1998;12:144-51. https://doi.org/10.1021/ef970115x.

[30] Dufour A, Celzard A, Fierro V, Martin E, Broust F, Zoulalian A. Catalytic decomposition of methane over a wood char concurrently activated by a pyrolysis gas. 
Appl Catal A Gen 2008;346:164-73. https://doi.org/10.1016/j.apcata.2008.05.023.

745

746

747

748

749

750

751

752

753

754

755

756

757

758

759

760

761

762

763

764

765

766

767

768

[31] Ranguin R, Jean-Marius C, Yacou C, Gaspard S, Feidt C, Rychen G, et al. Reduction of chlordecone environmental availability by soil amendment of biochars and activated carbons from lignocellulosic biomass. Environ Sci Pollut Res 2020. https://doi.org/10.1007/s11356-019-07366-2.

[32] Greco G, Videgain M, Di Stasi C, González B, Manyà JJ. Evolution of the mass-loss rate during atmospheric and pressurized slow pyrolysis of wheat straw in a bench-scale reactor. J Anal Appl Pyrolysis 2018;136:18-26. https://doi.org/10.1016/j.jaap.2018.11.007.

[33] Di Stasi C, Alvira D, Greco G, González B, Manyà JJ. Physically activated wheat straw-derived biochar for biomass pyrolysis vapors upgrading with high resistance against coke deactivation. Fuel 2019;255:115807. https://doi.org/10.1016/j.fuel.2019.115807.

[34] Jagiello J, Kenvin J, Celzard A, Fierro V. Enhanced resolution of ultra micropore size determination of biochars and activated carbons by dual gas analysis using N2 and CO2 with 2D-NLDFT adsorption models. Carbon 2019;144:206-15. https://doi.org/10.1016/j.carbon.2018.12.028.

[35] Sanchez-Sanchez A, Izquierdo MT, Medjahdi G, Ghanbaja J, Celzard A, Fierro V. Ordered mesoporous carbons obtained by soft-templating of tannin in mild conditions. Microporous Mesoporous Mater 2018;270:127-39. https://doi.org/10.1016/j.micromeso.2018.05.017.

[36] Matos J, Labady M, Albornoz A, Laine J, Brito JL. Catalytic effect of KOH on textural changes of carbon macro-networks by physical activation. J Mol Catal A Chem 2005;228:189-94. https://doi.org/10.1016/j.molcata.2004.09.039.

[37] Lozano-Castelló D, Calo JM, Cazorla-Amorós D, Linares-Solano A. Carbon activation 
with $\mathrm{KOH}$ as explored by temperature programmed techniques, and the effects of hydrogen. Carbon 2007;45:2529-36. https://doi.org/10.1016/j.carbon.2007.08.021.

771

[38] Ganga Devi T, Kannan MP. Calcium catalysis in air gasification of cellulosic chars. Fuel 1998;77:1825-30. https://doi.org/10.1016/S0016-2361(98)00038-6.

[39] Dehkhoda AM, Gyenge E, Ellis N. A novel method to tailor the porous structure of $\mathrm{KOH}$-activated biochar and its application in capacitive deionization and energy storage. Biomass Bioenergy 2016;87:107-21. https://doi.org/10.1016/j.biombioe.2016.02.023.

[40] Malekshahian M, Hill JM. Effect of pyrolysis and CO2 gasification pressure on the surface area and pore size distribution of petroleum coke. Energy Fuels 2011;25:52506. https://doi.org/10.1021/ef201231w.

[41] Montané D, Fierro V, Marêché JF, Aranda L, Celzard A. Activation of biomassderived charcoal with supercritical water. Microporous Mesoporous Mater 2009;119:53-9. https://doi.org/10.1016/j.micromeso.2008.09.040.

[42] Malekshahian M, Hill JM. Kinetic Analysis of CO2 Gasification of Petroleum Coke at High Pressures. Energy Fuels 2011;25:4043-8. https://doi.org/10.1021/ef2009259.

[43] Fermoso J, Stevanov C, Moghtaderi B, Arias B, Pevida C, Plaza MG, et al. Highpressure gasification reactivity of biomass chars produced at different temperatures. J Anal Appl Pyrolysis 2009;85:287-93. https://doi.org/10.1016/j.jaap.2008.09.017.

[44] Yip K, Tian F, Hayashi JI, Wu H. Effect of alkali and alkaline earth metallic species on biochar reactivity and syngas compositions during steam gasification. Energy Fuels 2010;24:173-81. https://doi.org/10.1021/ef900534n.

[45] Sueyasu T, Oike T, Mori A, Kudo S, Norinaga K, Hayashi JI. Simultaneous steam reforming of tar and steam gasification of char from the pyrolysis of potassium-loaded woody biomass. Energy Fuels 2012;26:199-208. https://doi.org/10.1021/ef201166a. 
[46] Jiang L, Hu S, Wang Y, Su S, Sun L, Xu B, et al. Catalytic effects of inherent alkali and alkaline earth metallic species on steam gasification of biomass. Int J Hydrogen Energy 2015;40:15460-9. https://doi.org/10.1016/j.ijhydene.2015.08.111.

[47] Matos J, Laine J. Ethylene conversion on activated carbon-supported NiMo catalysts: Effect of the support. Appl Catal A Gen 2003;241:25-38. https://doi.org/10.1016/S0926-860X(02)00427-1.

[48] Díaz K, García V, Matos J. Activated carbon supported Ni - Ca: Influence of reaction parameters on activity and stability of catalyst on methane reformation. Fuel 2007;86:1337-44. https://doi.org/10.1016/j.fuel.2006.05.011.

[49] Matos J, Díaz K, García V, Cordero TC, Brito JL. Methane transformation in presence of carbon dioxide on activated carbon supported nickel - calcium catalysts. Catalysis Lett. 2006;109:163-169. https://doi.org/10.1007/s10562-006-0073-3.

[50] Ducousso M, Weiss-Hortala E, Lyczko N, Nzihou A, Castaldi MJ. 110th Anniversary: Syngas Production Enhancement Using Calcium- And Potassium-Impregnated Chars. Ind Eng Chem Res 2019;58:15134-41. https://doi.org/10.1021/acs.iecr.9b02238.

[51] Figueiredo JL, Pereira MFR. The role of surface chemistry in catalysis with carbons. Catal Today 2010;150:2-7. https://doi.org/10.1016/j.cattod.2009.04.010.

[52] Kopyscinski J, Rahman M, Gupta R, Mims CA, Hill JM. K2CO3 catalyzed CO2 gasification of ash-free coal. Interactions of the catalyst with carbon in $\mathrm{N} 2$ and $\mathrm{CO} 2$ atmosphere. Fuel 2014;117:1181-9. https://doi.org/10.1016/j.fuel.2013.07.030.

[53] Li X, Liu J, Kong F, Liu X, Xu J, Chen H. Potassium-doped graphene for simultaneous determination of nitrite and sul fi te in polluted water. Electrochem Commun 2012;20:109-12. https://doi.org/10.1016/j.elecom.2012.04.014. 